\title{
Definicije naziva povezanih s pojedinačnim makromolekulama, makromolekulskim nakupinama, polimernim otopinama i amorfnim polimernim tvarima (III. dio) ${ }^{* * *}$
}

Prispjelo 30. studenoga 2015.

Prihvaćeno 18. svibnja 2016.

\section{Preporuke IUPAC 2014. \\ Preporuke HDKI i HKD 2016.}

Pripravila radna skupina u sastavu:

Robert Stepto*, Taihyun Chang, Pavel Kratochvil, Michael Hess,

Kazuyuki Horie, Takahiro Sato i Jiři Vohlídal

Preveo:

Marko Rogošić *

Sveučilište u Zagrebu, Fakultet kemijskog inženjerstva i tehnologije

\begin{abstract}
|| Sažetak
Ovaj dokument definira nazive povezane sa svojstvima pojedinačnih makromolekula, makromolekulskih nakupina, polimernih otopina i amorfnih polimernih tvari. U odjeljku o polimernim otopinama i amorfnim polimernim tvarima razmatraju se opće i termodinamičko nazivlje, razrijeđene otopine, fazno ponašanje, transportna svojstva, metode raspršenja svjetlosti i separacijske metode. Preporuke su revizija i proširenje nazivlja IUPAC-a objavljenog 1989., koje se ticalo pojedinačnih makromolekula, makromolekulskih nakupina i razrijeđenih polimernih otopina. Uvedeni su novi nazivi koji pokrivaju glavna teorijska i eksperimentalna saznanja do kojih se u međuvremenu došlo. Polielektroliti nisu uključeni.

\| Ključne riječi

Amorfni polimeri, polimerne mase, IUPAC-ov Odjel za polimere, makromolekulske nakupine, makromolekule, fazno ponašanje polimera, polimerne otopine, termodinamika polimera, svojstva raspršenja svjetlosti, separacijske metode, transportna svojstva
\end{abstract}

\section{Sadržaj}

3. Polimerne otopine i amorfne polimerne tvari

3.5. Svojstva raspršenja svjetlosti 381

3.6. Separacijske metode 381

4. Članstvo u podupirućim tijelima 384

5. Popis naziva 386

Literatura 386

Summary 400 401

*Prof. dr. sc. Marko Rogošić, mrogosic@fkit.hr

** Autor za korespondenciju: Robert Stepto, School of Materials, The University of Manchester, Manchester M1 7HS, UK, e-mail: rftstepto@ gmail.com.

*** Izvornik: Robert Stepto, Taihyun Chang, Pavel Kratochvíl, Michael Hess, Kazuyuki Horie, Takahiro Sato, Jiř̌ Vohlídal, Definitions of terms relating to individual macromolecules, macromolecular assemblies, polymer solutions, and amorphous bulk polymers (IUPAC Recommendations 2014), Pure Appl. Chem. 87(1) (2015) 71-120.

Recenzenti: Davor Kovačević, Branko Kunst, Ivan Šmit, Valerije Vrček

\section{Polimerne otopine i amorfne polimerne tvari}

\subsection{Svojstva raspršenja svjetlosti}

\section{Uvod - koherentno elastično raspršenje zračenja} (coherent elastic scattering of radiation)

Snop zračenja koji prolazi kroz neko sredstvo može oslabjeti i djelomično se raspršiti. Definicije koje slijede odnose se na slučajeve kada upadni snop slabi samo zbog raspršenja, energija raspršenog kvanta jednaka je energiji kvanta primarnog snopa (elastično raspršenje) i zadržani su fazni odnosi između neovisnih raspršivača (koherentno raspršenje). Ovaj odjeljak bavi se raspršenjem svjetlosti*, raspršenjem rendgenskog zračenja pri malim kutovima* i raspršenjem neutrona pri malim kutovima*. Pri raspršenju svjetlosti važna je polarizacija svjetlosti; ovdje se razmatra samo svjetlost polarizirana u ravnini, koja se naziva vertikalno polariziranom (v) ako je električni vektor snopa okomit na ravninu u kojoj su izvor, uzorak i detektor, odnosno 
horizontalno polariziranom (h) ako električni vektor leži u toj ravnini. Nepolarizirana svjetlost smatra se smjesom jednakih udjela $\mathbf{v}$ - $\mathbf{i} \mathbf{h}$-svjetlosti.

\subsection{1. jednolika disperzija ${ }^{p}$, uniformna disperzija ${ }^{d}$ (uniform dispersion)}

Disperzija čestica jednake veličine, oblika i konstitucije.

\subsection{2. nejednolika disperzija ${ }^{p}$, neuniformna disperzija ${ }^{d}$ (non-uniform dispersion)}

Disperzija čestica nejednake veličine, oblika ili konstitucije.

\subsection{3. statičko raspršenje svjetlosti \\ (static light scattering, SLS)}

Eksperimentalna metoda zasnovana na mjerenju vremenski uprosječenog intenziteta svjetlosti raspršene na polimernim otopinama ili disperzijama čestica pri različitim kutovima u odnosu na upadni snop.

Napomena 1: SLS je apsolutna metoda, tj. koja ne zahtijeva umjeravanje, za određivanje molarne mase makromolekulske tvari ili dispergiranih čestica.

Napomena 2: Mjerenje kutne ovisnosti vremenski uprosječenog intenziteta svjetlosti raspršene na razrijeđenoj otopini makromolekula ili na razrijeđenoj disperziji čestica koje nisu zanemarivo malene u odnosu na valnu duljinu upadne svjetlosti može poslužiti za određivanje prosječnoga polumjera vrtnje otopljenih makromolekula ili dispergiranih čestica.

Napomena 3: Mjerenje koncentracijske ovisnosti intenziteta svjetlosti raspršene na razrijeđenoj otopini makromolekula ili razrijeđenoj disperziji čestica pruža informaciju o termodinamičkom međudjelovanju otopljene tvari i otapala ili dispergiranih čestica i sredstva za dispergiranje preko drugog osmotskog virijalnog koeficijenta i, rjeđe, virijalnih koeficijenata višeg reda.

\subsection{4. dinamičko raspršenje svjetlosti} (dynamic light scattering, DLS)

kvazielastično raspršenje svjetlosti (quasi-elastic light scattering, QELS)

\section{fotonska korelacijska spektroskopija}

(photon-correlation spectroscopy, PCS)

Eksperimentalna metoda zasnovana na mjerenju vremenske autokorelacijske funkcije intenziteta svjetlosti raspršene na razrijeđenoj otopini makromolekula ili razrijeđenoj disperziji čestica.

Napomena: Osnovna informacija koja se može dobiti iz vremenske autokorelacijske funkcije ${ }^{12}$ polimerne otopine ili disperzije je: (i) za jednoliki polimer ili jednoliku disperziju, difuzijski koeficijent makromolekula ili dispergiranih čestica; (ii) za nejednoliki polimer ili nejednoliku disperziju, funkcija raspodjele difuzijskih koeficijenata makromolekula ili dispergiranih čestica.

\subsection{5. mala molekula (small molecule)}

Molekula mnogo manja od valne duljine zračenja u promatranom otapalu.

Napomena: Da bi se molekula smatrala malom, duljina svake od njezinih dimenzija mora biti manja od oko jedne dvadesetine primijenjene valne duljine.

\subsection{6. mala čestica (small particle)}

Čestica mnogo manja od valne duljine zračenja u promatranom sredstvu za dispergiranje.

Napomena: Da bi se čestica smatrala malom, duljina svake od njezinih dimenzija mora biti manja od oko jedne dvadesetine primijenjene valne duljine.

\subsection{7. velika molekula (large molecule)}

Molekula čija je veličina slična valnoj duljini zračenja u promatranom otapalu ili veća od nje.

Napomena: Molekula se smatra velikom ako duljina njezine najveće dimenzije premašuje oko jednu dvadesetinu primijenjene valne duljine.

\subsection{8. velika čestica (large particle)}

Čestica čija je veličina slična valnoj duljini zračenja u promatranom sredstvu za dispergiranje ili veća od nje.

Napomena: Čestica se smatra velikom ako duljina njezine najveće dimenzije premašuje oko jednu dvadesetinu primijenjene valne duljine.

\subsubsection{Rayleighovo raspršenje (Rayleigh scattering)}

Raspršenje svjetlosti na molekulama ili česticama koje su mnogo manje od valne duljine primijenjenog zračenja. ${ }^{3}$

Napomena 1: Rayleighovo raspršenje opaža se na malim molekulama i malim česticama, a može se opaziti i na velikim molekulama i velikim česticama, ako te nisu dovoljno velike da se opazi Mieovo raspršenje.

Napomena 2: Kod Rayleighova raspršenja intenzitet raspršenog zračenja pri promatranom kutu i udaljenosti od točke raspršenja razmjeran je $\lambda^{-4}$, gdje je $\lambda$ valna duljina upadnog zračenja.

\subsubsection{Mieovo raspršenje (u polimernoj znanosti)} (Mie scattering)

Raspršenje svjetlosti na molekulama ili česticama veličine koja je veća od približno polovice valne duljine primijenjenog zračenja.

Napomena 1: Za homogene je sfere taj fenomen strogo opisan Mieovom teorijom.

Napomena 2: Definicija je konzistentna s općenitijom iz lit. ${ }^{3}$. 


\subsubsection{1. kut raspršenja, $\theta$ (scattering angle) kut promatranja (angle of observation)}

Kut što ga zatvara produženi smjer upadnog snopa i pravac koji povezuje točku raspršenja i detektor.

\subsubsection{2. vektor raspršenja, $q$ (scattering vector) prijenos količine gibanja $^{p}$, prijenos momenta ${ }^{\mathrm{d}}$, (momentum transfer)}

Vektorska razlika između vektora širenja vala upadnoga i raspršenoga snopa, oba iznosa $2 \pi / \lambda$, gdje je $\lambda$ valna duljina raspršenog zračenja u promatranom otapalu ili sredstvu za dispergiranje.

Napomena: Iznos vektora raspršenja je $q=(4 \pi / \lambda) \sin (\theta / 2)$, gdje je $\lambda$ valna duljina raspršenog zračenja u sredstvu, a $\theta$ je kut raspršenja.

\subsubsection{3. prirast indeksa loma, $\partial n / \partial c$, jedinica: vidi napomenu 1 (refractive index increment)}

Diferencijal indeksa loma otopine, $n$, prema njezinoj koncentraciji, $c$.

Napomena 1: Koncentracija se otopine najčešće izražava masenom koncentracijom, molalitetom ili volumnim udjelom. Ako je iskazana masenom koncentracijom ili molalitetom, odgovarajući se indeksi loma nazivaju specifični prirast indeksa loma* odnosno molalni prirast indeksa loma*. Jedinica za $\partial n / \partial c$ je recipročna jedinici primijenjene koncentracije, obično $\mathrm{cm}^{3} \mathrm{~g}^{-1}$ za masenu koncentraciju, odnosno $\mathrm{g} \mathrm{mol}^{-1}$ za molalitet. Odgovarajuće $\mathrm{SI}$ jedinice su $\mathrm{m}^{3} \mathrm{~kg}^{-1}$, odnosno $\mathrm{kg} \mathrm{mol}^{-1}$.

\subsubsection{4. izorefrakcijski (isorefractive)}

Pridjev koji opisuje komponente višekomponentnog sustava koje jedna prema drugoj imaju priraste indeksa loma jednake nuli.

3.5.15. Rayleighov omjer, $R(\theta), R_{\theta}$ jedinica: $\mathrm{cm}^{-1}$ ili $\mathrm{SI}$ jedinica: $\mathrm{m}^{-1}$ (Rayleigh ratio)

poprečni presjek (kod raspršenja neutrona pri malim kutovima) (cross-section)

Veličina koja se primjenjuje za karakterizaciju intenziteta raspršene svjetlosti pri kutu raspršenja, $\theta$, definira se kao $R(\theta)=i_{\theta} r^{2} /\left(I_{0} f V_{\theta}\right)$, gdje je $I_{0}$ intenzitet upadnog zračenja, $i_{\theta}$ je intenzitet raspršenog zračenja u promatranom volumenu raspršenja, $V_{\theta}$, pri kutu $\theta$ i udaljenosti $r$ od točke raspršenja. Faktor $f$ uzima u obzir polarizacijske fenomene.

Napomena 1: Vrijednost $f$ ovisi o vrsti primijenjenog zračenja:

(i) za statičko raspršenje svjetlosti, ovisno o polarizaciji upadnog snopa, $f=1$ za vertikalno polariziranu svjetlost, $f=\cos ^{2} \theta$ za horizontalno polariziranu svjetlost, $f=\left(1+\cos ^{2} \theta\right) / 2$ za nepolariziranu svjetlost;

(ii) za raspršenje neutrona pri malim kutovima, $f=1$;

(iii) za raspršenje rendgenskog zračenja pri malim kutovi- ma, $f \approx 1$, ako je $\theta$ manji od približno $5^{\circ}$.

Napomena 2: $\bigcup$ fizici, faktor $f$ se ne mora uključiti u definiciju Rayleighova omjera.

Napomena 3: $V_{\theta}$ je razmjeran s $1 / \sin \theta$, ne računajući neke manje korekcijske faktore.

3.5.16. ekscesni Rayleighov omjer, $\Delta R(\theta), \Delta R_{\theta}$, jedinica: $\mathrm{cm}^{-1}$ ili SI jedinica: $\mathrm{m}^{-1}$ (excess Rayleigh ratio)

Razlika Rayleighova omjera za razrijeđenu otopinu ili razrijeđenu disperziju i omjera čistog otapala ili sredstva za dispergiranje pri istom kutu raspršenja.

Napomena: Vidi definiciju 3.5.17.

\subsubsection{7. ekscesno raspršenje (excess scattering)}

Razlika intenziteta raspršene svjetlosti razrijeđene otopine ili razrijeđene disperzije u odnosu na raspršenje u čistom otapalu ili sredstvu za dispergiranje pri istom kutu raspršenja.

Napomena: Vidi definiciju 3.5.16.

3.5.18. zamućenost ${ }^{\mathrm{p}}$, turbidnost ${ }^{\mathrm{d}}, \tau$, jedinica: $\mathrm{cm}^{-1}$ ili SI jedinica: $\mathrm{m}^{-1}$ (turbidity)

Mjera prividne apsorbancije upadnog zračenja uslijed raspršenja, po jediničnoj duljini puta upadnog snopa, prema:

$$
\tau=-(1 / d) \ln \left(I / I_{0}\right),
$$

gdje je $I_{0}$ intenzitet upadnog zračenja, $I$ je intenzitet prolaznog (neraspršenog) zračenja, a d je debljina sloja sredstva koje rasipa.

Napomena: Za male čestice mutnoća je izravno razmjerna Rayleighovu omjeru.

\subsubsection{9. turbidimetrijska titracija (turbidimetric titration)}

Proces u kojemu se vrlo razrijeđenoj polimernoj otopini postupno dodaje taložno sredstvo i pritom se mjeri zamućenost, odnosno intenzitet raspršene svjetlosti na fino dispergiranim česticama faze bogate polimerom kao funkcija količine dodanog taložnog sredstva.

\subsubsection{0. čestična funkcija raspršenja, $P(\theta), P_{\theta}$ (particle scattering function) \\ čestični faktor raspršenja (particle scattering factor) \\ faktor oblika (form factor)}

Omjer intenziteta zračenja raspršenog pri kutu raspršenja $\theta$ prema intenzitetu zračenja raspršenog pri $\theta=0, \mathrm{tj}$.:

$$
P(\theta) \equiv \frac{R(\theta)}{R(0)} .
$$

Napomena: Matematički gledano, faktor oblika je Fourierova transformacija radijalne funkcije raspodjele raspršujućih elemenata unutar molekule ili čestice. 


\subsubsection{1. statički strukturni faktor (static structure factor)}

Funkcija koja opisuje ovisnost relativnog intenziteta raspršenja o iznosu vektora raspršenja, q, za polimernu otopinu ili disperziju.

Napomena: Statički strukturni faktor uzima u obzir interferenciju raspršenoga zračenja unutar pojedinačnih makromolekula ili pojedinačnih dispergiranih čestica koju opisuje faktor oblika te interferenciju raspršenog zračenja s različitih makromolekula ili različitih dispergiranih čestica koja odražava uređenost položaja makromolekula, odnosno dispergiranih čestica u otopini.

\subsubsection{2. dinamički strukturni faktor} (dynamic structure factor)

Funkcija koja opisuje vremensku ovisnost relativnog intenziteta raspršenja o iznosu vektora raspršenja.

Napomena: Vrijednost dinamičkog strukturnog faktora karakterizira različite načine gibanja polimernih molekula ili dispergiranih čestica i njihovih dijelova te također karakterizira vremenski ovisnu interferenciju raspršenja, koja s druge strane odražava vremensku ovisnost uređenosti položaja makromolekula, odnosno dispergiranih čestica u otopini. U dinamičkom raspršenju svjetlosti, vrijednost dinamičkog strukturnog faktora može se izvesti iz vremenske autokorelacijske funkcije.

\subsubsection{Zimmov dijagram (Zimm plot)}

Grafički prikaz podataka o intenzitetu raspršenog zračenja s velikih čestica u otopini zasnovan na jednadžbi:

$$
\frac{K C}{\Delta R(\theta)}=\frac{1}{M_{m} P(\theta)}+2 A_{2} C+\ldots ;
$$

$K c / \Delta R(\theta)$ crta se u ovisnosti o linearnoj kombinaciji $\sin ^{2}(\theta / 2)$ i $c$, gdje je $\theta$ kut raspršenja, $c$ je masena koncentracija otopljene tvari, $\Delta R(\theta)$ je ekscesni Rayleighov omjer, $P(\theta)$ je čestična funkcija raspršenja koja uključuje, za veliku molekulu ili veliku česticu, z-prosjek polumjera vrtnje i polinomna je funkcija $\sin ^{2}(\theta / 2)$. $K$ ovisi o otopljenoj tvari, otapalu, temperaturi i vrsti primijenjenog zračenja, $M_{\mathrm{m}}$ je maseni prosjek molarne mase, a $A_{2}$ je drugi virijalni koeficijent kemijskog potencijala.

Napomena 1: Zimmov se dijagram primjenjuje za istodobno određivanje $M_{m}, A_{2}$ te, za veliku molekulu ili veliku česti$\mathrm{cu}, \mathrm{z}$-prosjeka srednjeg kvadrata polumjera vrtnje.

Napomena 2: Često se primjenjuje nekoliko modifikacija Zimmova dijagrama; najuobičajenija uključuje ekscesno raspršenje umjesto ekscesnog Rayleighova omjera.

Napomena 3: Zimmov je dijagram dvodimenzijski prikaz plohe $K c / \Delta R(\theta)=f\left[\sin ^{2}(\theta / 2), c\right]$ koji daje ovisnost $K c / \Delta R(\theta)$ o kutu raspršenja, $\theta$, i koncentraciji, $c$. Konstruira se iz vrijednosti $K c / \Delta R(\theta)$ za otopine različitih koncentracija, od kojih se svaka mjeri pri istom nizu kutova raspršenja.

\subsubsection{Guinierov dijagram (Guinier plot)}

Grafički prikaz podataka o intenzitetu raspršenog zračenja $\mathrm{s}$ velikih čestica u otopini, dobivenih pri različitim kutovi- ma ali pri istoj koncentraciji, gdje se $\log [\Delta R(\theta)]$ ili $\log [P(\theta)]$ crta kao funkcija $\sin ^{2}(\theta / 2)$, odnosno $q^{2} ; \Delta R(\theta)$ je ekscesni Rayleighov omjer, $P(\theta)$ je čestična funkcija raspršenja, $\theta$ je kut raspršenja, a $q$ je iznos vektora raspršenja.

Napomena: Guinierov se dijagram obično primjenjuje za određivanje srednjeg kvadrata polumjera vrtnje.

\subsubsection{Kratkyjev dijagram (Kratky plot)}

Grafički prikaz podataka o intenzitetu raspršenog zračenja, dobivenih pri različitim kutovima ali pri istoj koncentraciji, gdje se $\sin ^{2}(\theta / 2) \Delta R(\theta)$ crta kao funkcija $\sin (\theta / 2)$ ili se $q^{2} \Delta R(\theta)$ crta kao funkcija $q$; za definicije simbola vidi definiciju 3.5.24.

Napomena: Kratkyjev se dijagram primjenjuje za određivanje molekulskog oblika.

\subsubsection{6. disimetrija raspršenja, $z\left(\theta_{1}, \theta_{2}\right)$ (dissymmetry of scattering)}

Omjer dvaju Rayleighovih omjera pri različitim kutovima raspršenja, tj. $z\left(\theta_{1}, \theta_{2}\right)=R\left(\theta_{1}\right) / R\left(\theta_{2}\right)$, gdje je $\theta_{1}<\theta_{2}$.

Napomena: Kutovi $\theta_{1}$ i $\theta_{2}$ moraju se specificirati; u raspršenju svjetlosti uobičajeno je da je $\theta_{2}=180^{\circ}-\theta_{1}$ te je najčešće $\theta_{1}=45^{\circ}$ i $\theta_{2}=135^{\circ}$.

\subsubsection{7. depolarizacija raspršenog svjetla (depolarization of scattered light)}

Fenomen koji je posljedica činjenice da električni vektori upadnog i raspršenog snopa nisu koplanarni jer svjetlost vertikalno (horizontalno) polariziranog upadnog snopa nakon raspršenja sadrži i horizontalnu (vertikalnu) komponentu.

Napomena: Fenomen nastaje ponajprije zbog anizotropije polarizabilnosti sredstva koje rasipa svjetlost.

\subsection{Separacijske metode}

\subsection{1. frakcioniranje (fractionation)}

Proces kojim se odjeljuju makromolekulske vrste međusobno različite po nekim obilježjima (kemijski sastav, relativna molekulska masa, grananje, stereoregularnost itd.).

\subsection{2. faza siromašna polimerom (polymer-poor phase) razrijeđena faza (dilute phase)}

Faza dvofaznoga ravnotežnog sustava sastavljenog od polimera i niskomolekulske tvari u kojoj je koncentracija polimera manja.

Napomena: Ne preporučuje se upotreba izraza sol-faza ${ }^{n^{*}}$.

\subsection{3. faza bogata polimerom (polymer-rich phase) koncentrirana faza (concentrated phase)}

Faza dvofaznoga ravnotežnog sustava sastavljenog od po- 
limera i niskomolekulske tvari u kojoj je koncentracija polimera veća.

Napomena: Ne preporučuje se upotreba izraza gel-faza ${ }^{\mathrm{n}^{*}}$.

\subsection{4. taložno frakcioniranje ${ }^{\mathrm{p}}$, precipitacijsko frakcioniranje $^{d}$ (precipitation fractionation) frakcijsko taloženje ${ }^{p}$, frakcijska precipitacija ${ }^{n}$ (fractional precipitation)}

Proces u kojem se polimerna tvar sastavljena od makromolekula čija različita obilježja utječu na topljivost odjeljuje iz otopine u frakcije postupnim smanjenjem moći otapanja otapala, što rezultira ponavljanim nastajanjem dvofaznog sustava u kojemu se slabije topljive komponente koncentriraju u fazi bogatoj polimerom.

\subsection{5. ekstrakcijsko frakcioniranje (extraction fractionation)}

Proces u kojem se polimerni materijal sastavljen od makromolekula čija različita obilježja utječu na topljivost odjeljuje iz faze bogate polimerom u frakcije postupnim povećanjem moći otapanja otapala, što rezultira ponavljanim nastajanjem dvofaznog sustava u kojemu se topljivije komponente koncentriraju u fazi siromašnoj polimerom.

\subsection{6. kromatografija isključenjem po veličini (size-exclusion chromatography, SEC)}

Separacijska tehnika u kojoj se odjeljivanje molekula ili čestica odvija uglavnom prema njihovu ekvivalentnom hidrodinamičkom volumenu, na poroznome neadsorbirajućem materijalu čije su pore veličinom približno jednake efektivnim dimenzijama otopljenih molekula koje se odjeljuju.

\subsection{7. kromatografija na propusnom gelu} (gel-permeation chromatography, GPC)

Kromatografija isključenjem po veličini u kojoj je porozni neadsorbirajući materijal gel.

\subsection{8. granica isključenja molarne mase}

(molar-mass exclusion limit)

\section{granica isključenja molekulske težine ${ }^{n}$}

(molecular-weight exclusion limit)

Maksimalna vrijednost molarne mase ili molekulske težine ${ }^{\mathrm{n}}$ molekula ili čestica, u sustavu polimer-otapalo ili u disperziji, koje mogu ulaziti u pore poroznog neadsorbirajućeg materijala primijenjenog u kromatografiji isključenjem po veličini.

Napomena: Za čestice molarne mase ili molekulske težine ${ }^{n}$ veće od granice isključenja separacija kromatografijom isključenja po veličini nije djelotvorna.

\subsection{9. vrijeme eluiranja, $t_{\mathrm{e}}, \mathrm{SI}$ jedinica: $\mathrm{s}$ (elution time)}

Vrijeme proteklo od injektiranja uzorka u kromatografsku podlogu do bilježenja određenog signala detektora nakon prolaska uzorka kroz podlogu.

3.6.10. volumen eluiranja ${ }^{\mathrm{p}}$, obujam eluiranja $^{\mathrm{d}}, V_{\mathrm{e}}$, jedinica: $\mathrm{cm}^{3}$ ili $\mathrm{SI}$ jedinica: $\mathrm{m}^{3}$ (elution volume)

Volumen otapala protekloga kroz kromatografsku podlogu od injektiranja uzorka do bilježenja određenog signala detektora nakon prolaska uzorka kroz podlogu.

\subsubsection{1. vrijeme zadržavanja, $t_{\mathrm{R}}$}

SI jedinica: $s$ (retention time)

Vrijeme eluiranja pri maksimumu elucijskog vrha.

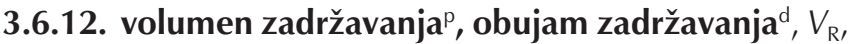
jedinica: $\mathrm{cm}^{3}$ ili SI jedinica: $\mathrm{m}^{3}$ (retention volume)

Volumen eluiranja pri maksimumu elucijskog vrha.

\subsubsection{3. univerzalno umjeravanje $\mathrm{e}^{\mathrm{p}}$, univerzalna kalibracija $^{\mathrm{d}}$ (universal calibration)}

Umjeravanje kolona za kromatografiju isključenjem po veličini zasnovano na spoznaji da je volumen zadržavanja molekule ili čestice obično jednoznačna funkcija prikladnoga dimenzijskog parametra veličine te molekule ili čestice, neovisna o njezinoj kemijskoj prirodi i konstituciji.

Napomena: Kao prikladan dimenzijski parametar široko se primjenjuje umnožak intrinzične viskoznosti i molarne

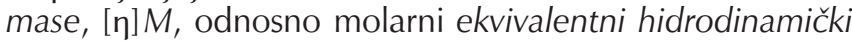
volumen, vidi definiciju 3.4.30.

\subsubsection{4. funkcija širenja (spreading function)}

Detektorski signal kao funkcija vremena eluiranja ili volumena eluiranja, opažen pri izlazu iz kromatografske kolone, nastao nakon trenutnog injektiranja uzorka jednolikoga polimera.

\subsubsection{5. broj teorijskih odsječaka, $N$ (plate number)}

Značajka djelotvornosti kromatografske kolone iskazana širenjem vrpce, definirana kao $N=8 \ln 2\left(t_{R} / W_{h}\right)^{2}$, gdje je $t_{R}$ vrijeme zadržavanja pojedinog niskomolekulskog spoja, a $w_{\mathrm{h}}$ je vremenski interval koji odgovara duljini dužine koju pravac paralelan s baznom linijom pri $50 \%$ visine vrha odsjeca s dva njegova kraka.

Napomena: Definicija je sukladna s onom iz lit. ${ }^{3}$.

3.6.16. visina teorijskog odsječka, $H$, jedinica: $\mathrm{cm}$ ili SI jedinica: $\mathrm{m}$ (plate height)

visina ekvivalentna teorijskom odsječku (height equivalent to a theoretical plate, HETP)

Duljina kromatografske kolone $(L)$ podijeljena s brojem teorijskih odsječaka $(N), \mathrm{tj} . H=L / N$.

Napomena: Definicija je sukladna s onom iz lit. ${ }^{3}$. 


\section{4. Članstvo u nadležnom tijelu pokrovitelja}

Članovi Odbora IUPAC-ova Odjela za polimere u razdoblju 2010. - 2011. bili su:

predsjednik: C. K. Ober (SAD); potpredsjednik: M. Buback (Njemačka); tajnik: M. Hess (Njemačka); naslovni članovi: D. Dijkstra (Njemačka); R. G. Jones (Ujedinjena Kraljevina); P. Kubisa (Poljska); G. T. Russell (Novi Zeland); M. Sawamoto (Japan); R. F. T. Stepto (Ujedinjena Kraljevina), J.-P. Vairon (Francuska); pridruženi članovi: D. Berek (Slovačka); J. He (Kina); R. Hiorns (Francuska); W. Mormann (Njemačka); D. Smith (Sjedinjene Američke Države); J. Stejskal (Češka); nacionalni predstavnici: K.-N. Chen (Tajvan); G. Galli (Italija); J. S. Kim (Južna Koreja); G. Moad (Australija); M. Raza Shah (Pakistan); R. P. Singh (Indija); W. M. Z. B. Wan Yunus (Malezija); Y. Yagci (Turska); M. Žigon (Slovenija).

Članovi Pododbora za nazivlje polimera (do 2005. Pododbor za nazivlje makromolekula) u razdoblju 2005. - 2012. bili su:

Predsjednik: M. Hess (Njemačka) do 2005.; R. G. Jones (Ujedinjena Kraljevina) od 2006.; tajnik: R. G. Jones (Uje- dinjena Kraljevina) do 2005.; M. Hess (Njemačka) 2006. - 2007.; T. Kitayama (Japan) 2008. - 2009.; R. Hiorns (Francuska) od 2010.; članovi: G. Allegra (Italija); M. Barón (Argentina); T. Chang (Južna Koreja); A. Fradet (Francuska); K. Hatada (Japan); J. He (Kina); K.-H. Hellwich (Njemačka); P. Hodge (Ujedinjena Kraljevina); K. Horie (Japan); A. D. Jenkins (Ujedinjena Kraljevina); J.-Il Jin (Južna Koreja); J. Kahovec (Češka); P. Kratochvíl (Češka); P. Kubisa (Poljska); S. V. Meille (Italija); I. Meisel (Njemačka); W. V. Metanomski (Sjedinjene Američke Države); I. Mita (Japan); G. Moad (Australija); W. Mormann (Njemačka); C. K. Ober (Sjedinjene Američke Države); S. Penczek (Poljska); L. P. Rebelo (Portugal); M. Rinaudo (Francuska); C. dos Santos (Brazil); M. Schubert (Sjedinjene Američke Ddržave); F. Schué (Francuska); S. Slomkowski (Poljska); R. F. T. Stepto (Ujedinjena Kraljevina); V. P. Šibajev (Rusija); I. Šopov (Bugarska); D. Tabak (Brazil); J.-P. Vairon (Francuska); M. Vert (Francuska); J. Vohlídal (Češka); E. S. Wilks (Sjedinjene Američke Države); W. J. Work (Sjedinjene Američke Države).

Ovaj je rukopis pripremljen u okviru IUPAC-ova projekta 2005-005-2-400.

\section{Popis naziva ${ }^{13,14}$}

Tablica 1 - Hrvatski nazivi abecednim redom

\begin{tabular}{|c|c|c|c|}
\hline Hrvatski naziv (abecednim redom) & Engleski naziv & Simbol & $\begin{array}{l}\text { Broj } \\
\text { definicije }\end{array}$ \\
\hline antiperiplanarni konformeri* & antiperiplanar conformers & & 1.9. \\
\hline Archibaldova metoda & Archibald's method & & 3.4.12. \\
\hline binodala (u polimernoj znanosti) & binodal & & 3.3.3. \\
\hline binodalna krivulja & binodal curve & & 3.3.3. \\
\hline${\text { birefringencija strujanja }{ }^{n}}$ & flow birefringence & & 3.4.7. \\
\hline broj teorijskih odsječaka & plate number & $N$ & 3.6.15. \\
\hline brojčana funkcija raspodjele & number-distribution function & $f_{\mathrm{n}}$ & 2.17 \\
\hline brojčana raspodjela & number distribution & & 2.17 \\
\hline brojčani prosjek molarne mase & number-average molar mass & $M_{\mathrm{n}}$ & 2.8 \\
\hline brojčani prosjek molekulske težine ${ }^{n}$ & number-average molecular weight & $M_{\mathrm{r}, \mathrm{n}}$ & 2.8 . \\
\hline brojčani prosjek relativne molarne mase & number-average relative molar mass & $M_{\mathrm{r}, \mathrm{n}}$ & 2.8. \\
\hline brojčani prosjek relativne molekulske mase & number-average relative molecular mass & $M_{\mathrm{r}, \mathrm{n}}$ & 2.8. \\
\hline cijevni model & tube model & & 3.4 .44 \\
\hline crvoliki lanac & worm-like chain & & 1.43. \\
\hline čestična funkcija raspršenja & particle scattering function & $P(\theta), P_{\theta}$ & 3.5.20. \\
\hline čestični faktor raspršenja & particle scattering factor & & 3.5.20. \\
\hline depolarizacija raspršenog svjetla & depolarization of scattered light & & 3.5.27. \\
\hline diferencijalna brojčana funkcija raspodjele & differential number-distribution function & & 2.17 \\
\hline diferencijalna brojčana raspodjela & differential number distribution & & 2.17 \\
\hline diferencijalna funkcija raspodjele ${ }^{*}$ & differential distribution function & & 2.16 \\
\hline diferencijalna masena funkcija raspodjele & differential mass-distribution function & & 2.19 . \\
\hline diferencijalna masena raspodjela & differential mass distribution & & 2.19 . \\
\hline diferencijalna raspodjela* & differential distribution & & 2.16 \\
\hline difuzijski koeficijent & diffusion coefficient & & 3.4.3. \\
\hline dinamički strukturni faktor & dynamic structure factor & & 3.5 .22 \\
\hline dinamičko raspršenje svjetlosti & dynamic light scattering, DLS & & 3.5.4. \\
\hline disimetrija raspršenja & dissymmetry of scattering & $z\left(\theta_{1}, \theta_{2}\right)$ & 3.5.26. \\
\hline disperznost & dispersity & $\oslash$ & 2.28 \\
\hline
\end{tabular}




\begin{tabular}{|c|c|c|c|}
\hline Hrvatski naziv (abecednim redom) & Engleski naziv & Simbol & $\begin{array}{l}\text { Broj } \\
\text { definicije }\end{array}$ \\
\hline disperznost molarne mase & molar-mass dispersity & $\bigoplus_{M}$ & 2.26 \\
\hline disperznost molekulske težine ${ }^{\mathrm{n}}$ & molecular-weight dispersity & & 2.26 . \\
\hline disperznost relativne molarne mase & relative-molar-mass dispersity & & 2.26 . \\
\hline disperznost relativne molekulske mase & relative-molecular-mass dispersity & & 2.26 . \\
\hline disperznost stupnja polimerizacije & degree-of-polymerisation dispersity & $\bigoplus_{\mathrm{x}}$ & 2.27 \\
\hline djelomično propustan & partial free-draining, partially draining & & 3.4.28. \\
\hline donja kritična temperatura otopine, DKTO & lower critical solution temperature, LCST & & 3.3.10. \\
\hline dugolančana grana & long-chain branch & & 1.47. \\
\hline duljina ekvivalentne slobodne poveznice ${ }^{n}$ & freely jointed link length & & 1.38. \\
\hline duljina konture & contour length & $r_{\text {max }}$ & 1.35. \\
\hline duljina Kuhnova odsječka & Kuhn segment length & $I^{\prime}, I_{\mathrm{K}}$ & 1.38. \\
\hline \multicolumn{4}{|l|}{$\begin{array}{l}\text { duljina Kuhnova segmenta }{ }^{n} \rightarrow \text { duljina Kuhnova } \\
\text { odsječka }^{p}\end{array}$} \\
\hline duljina potpuno ispruženog lanca & fully extended chain length & & 1.35 \\
\hline duljina statističkog odsječka & statistical segment length & $I^{\prime}, I_{\mathrm{K}}$ & 1.38. \\
\hline \multicolumn{4}{|l|}{$\begin{array}{l}\text { duljina statističkog segmenta }{ }^{n} \rightarrow \text { duljina statističkog } \\
\text { odsječka }^{p}\end{array}$} \\
\hline dvolom pri strujanju kapljevina ${ }^{p}$ & streaming birefringence & & 3.4.7. \\
\hline efektivna duljina veze & effective bond length & $b$ & 1.33. \\
\hline ekscesni Rayleighov omjer & excess Rayleigh ratio & $\Delta R(\theta), \Delta R_{\theta}$ & 3.5.16. \\
\hline ekscesno raspršenje & excess scattering & & 3.5 .17 \\
\hline ekspanzijski faktor & expansion factor & $\alpha_{r}, \alpha_{s}, \alpha_{D}, \alpha_{\eta}$ & 3.2.11. \\
\hline ekstrakcijsko frakcioniranje & extraction fractionation & & 3.6.5. \\
\hline ekvivalentna slobodna poveznican ${ }^{\mathrm{n}}$ & equivalent freely jointed link & & 1.37. \\
\hline ekvivalentni hidrodinamički polumjer & equivalent hydrodynamic radius & & 3.4.31. \\
\hline ekvivalentni hidrodinamički volumen & equivalent hydrodynamic volume & & 3.4.30. \\
\hline ekvivalentni slobodno povezani lanac & equivalent freely jointed chain & & 1.36. \\
\hline faktor ekspanzije lanca & chain expansion factor & & 3.2.11. \\
\hline faktor oblika & form factor & & 3.5.20. \\
\hline faktor sažimanja & contraction factor & & 1.48. \\
\hline faktor sažimanja polumjera vrtnje & radius of gyration contraction factor & & 1.48 \\
\hline faza bogata polimerom & polymer-rich phase & & 3.6.3. \\
\hline faza siromašna polimerom & polymer-poor phase & & 3.6 .2 . \\
\hline Flory-Foxova jednadžba & Flory-Fox equation & & 3.4.38. \\
\hline Flory-Foxova pretpostavka & Flory-Fox assumption & & 3.4.37. \\
\hline Flory-Hugginsova teorija & Flory-Huggins theory & & 3.1 .12 \\
\hline Flory-Huggins-Stavermanova teorija & Flory-Huggins-Staverman theory & & 3.1 .12 \\
\hline Floryjeva funkcija & Flory function & & 3.4.39. \\
\hline Floryjeva raspodjela & Flory distribution & & 2.22 \\
\hline fotonska korelacijska spektroskopija & photon-correlation spectroscopy, PCS & & 3.5.4. \\
\hline \multicolumn{4}{|l|}{ frakcijska precipitacija ${ }^{\mathrm{n}} \rightarrow$ frakcijsko taloženje $^{\mathrm{p}}$} \\
\hline frakcijsko taloženje $\mathrm{e}^{\mathrm{p}}$ & fractional precipitation & & 3.6.4. \\
\hline frakcioniranje & fractionation & & 3.6.1. \\
\hline funkcija gustoće vjerojatnosti* & probability density function & & 2.16 \\
\hline funkcija raspodjele (u polimernoj znanosti) & distribution function & & 2.16. \\
\hline funkcija širenja & spreading function & & 3.6 .14 . \\
\hline$g^{\prime}$-faktor & $g^{\prime}$-factor & $g^{\prime}$ & 1.49. \\
\hline Gaussovo klupko & Gaussian coil & & 1.42. \\
\hline gel-faza $^{n^{*}}$ & gel phase & & 3.6.3. \\
\hline geometrijski faktor sažimanja & geometric contraction factor & & 1.48. \\
\hline g-faktor & $g$-factor & $g$ & 1.48. \\
\hline gmizanje & reptation & & 3.4 .43 \\
\hline gornja kritična temperatura otopine, GKTO & upper critical solution temperature, UCST & & 3.3.11. \\
\hline
\end{tabular}




\begin{tabular}{|c|c|c|c|}
\hline Hrvatski naziv (abecednim redom) & Engleski naziv & Simbol & $\begin{array}{l}\text { Broj } \\
\text { definicije }\end{array}$ \\
\hline granica isključenja molarne mase & molar-mass exclusion limit & & 3.6 .8 \\
\hline granica isključenja molekulske težine ${ }^{n}$ & molecular-weight exclusion limit & & 3.6.8. \\
\hline granični viskoznosni broj $^{\text {n}}$ & limiting viscosity number & & 3.4.19. \\
\hline Guinierov dijagram & Guinier plot & & 3.5 .24 \\
\hline heterogenost sastava & compositional heterogeneity & & 2.1 \\
\hline hidrodinamički ekvivalentna kugla & hydrodynamically equivalent sphere & & 3.4.29. \\
\hline hidrodinamički faktor sažimanja & hydrodynamic contraction factor & & 1.49. \\
\hline hidrodinamičko međudjelovanje & hydrodynamic interaction & & 3.4 .25 . \\
\hline hi-parametar & chi parameter & $\chi$ & 3.1.13. \\
\hline hi-parametar međudjelovanja & chi interaction parameter & & 3.1.13. \\
\hline Hugginsov koeficijent & Huggins coefficient & $k_{\mathrm{H}}$ & 3.4.21. \\
\hline Hugginsova jednadžba & Huggins equation & & 3.4.20 \\
\hline indeks polidisperznosti* & polydispersity index & & 2.26 \\
\hline inherentna viskoznost & inherent viscosity & $\eta_{\text {inh }}$ & 3.4.18. \\
\hline integralna brojčana funkcija raspodjele & integral number-distribution function & & 2.18 \\
\hline integralna brojčana raspodjela & integral number distribution & & 2.18. \\
\hline integralna funkcija raspodjele ${ }^{*}$ & integral distribution function & & 2.16 \\
\hline integralna masena funkcija raspodjele & integral mass-distribution function & & 2.20 \\
\hline integralna masena raspodjela & integral mass distribution & & 2.20 \\
\hline integralna raspodjela* & integral distribution & & 2.16. \\
\hline intrinzična viskoznost & intrinsic viscosity & {$[\eta]$} & 3.4.19. \\
\hline isključeni volumen makromolekule & excluded volume of a macromolecule & & 3.2.9. \\
\hline isključeni volumen segmenta & excluded volume of a segment & & 3.2.8. \\
\hline izopiknički & isopycnic & & 3.4.14. \\
\hline izorefrakcijski & isorefractive & & 3.5.14. \\
\hline jednolik* & uniform & & 2.3. \\
\hline jednolika disperzijap $^{p}$ & uniform dispersion & & 3.5.1. \\
\hline jednoliki polimerp ${ }^{p}$ & uniform polymer & & 2.3. \\
\hline jezgrenje faznog razdvajanja ${ }^{p}$ & nucleation of phase separation & & 3.3.6. \\
\hline jezgrenje $^{*}$ & nucleation & & 3.3.6. \\
\hline karakteristični omjer & characteristic ratio & $\begin{array}{l}C_{n}\left(C_{\infty} \text { kad }\right. \\
n \rightarrow \infty)\end{array}$ & 1.28 \\
\hline Kirkwood-Risemanova teorija & Kirkwood-Riseman theory & & 3.4.36. \\
\hline koeficijent trenja & frictional coefficient & & 3.4.2. \\
\hline koncentracija preklapanja $^{n}$ & overlap concentration & & 3.1 .2$. \\
\hline koncentrirana faza & concentrated phase & & 3.6.3. \\
\hline koncentrirana otopina & concentrated solution & & 3.1.4. \\
\hline konformacija lanca & chain conformation & & 1.10 \\
\hline konformacijsko stanje veze (u polimernoj znanosti) & bond-conformational state & & 1.9. \\
\hline konformer & conformer & & 1.7. \\
\hline konstitucijska heterogenost & constitutional heterogeneity & & 2.2 \\
\hline korekcija zbog polimolekularnosti & polymolecularity correction & & 2.14 \\
\hline $\begin{array}{l}\text { korijen srednjeg kvadrata neometane udaljenosti } \\
\text { krajeva }\end{array}$ & $\begin{array}{l}\text { root-mean-square unperturbed end-to-end } \\
\text { distance }\end{array}$ & $\left\langle r_{0}^{2}\right\rangle^{1 / 2}$ & 1.26. \\
\hline korijen srednjeg kvadrata neometanog polumjera vrtnje & root-mean-square unperturbed radius of gyration & $\left\langle S_{\mathrm{o}}{ }^{2}\right\rangle^{1 / 2}$ & 1.18. \\
\hline korijen srednjeg kvadrata polumjera vrtnje & root-mean-square radius of gyration & $\left\langle s^{2}\right\rangle^{1 / 2}, R_{\mathrm{g}}$ & 1.16. \\
\hline korijen srednjeg kvadrata udaljenosti krajeva & root-mean-square end-to-end distance & $\left\langle r^{2}\right\rangle^{1 / 2}$ & 1.24 \\
\hline $\begin{array}{l}\text { korijen srednjeg kvadrata udaljenosti krajeva slobodno } \\
\text { rotirajućeg lanca }\end{array}$ & $\begin{array}{l}\text { root-mean-square end-to-end distance of a freely } \\
\text { rotating chain }\end{array}$ & $\left\langle r_{0, f}^{2}\right\rangle^{1 / 2}$ & 1.30 \\
\hline Kraemerov koeficijent & Kraemer coefficient & $k_{\mathrm{K}}$ & 3.4.23. \\
\hline Kraemerova jednadžba & Kraemer equation & & 3.4 .22 \\
\hline kratkolančana grana & short-chain branch & & 1.46. \\
\hline Kratkyjev dijagram & Kratky plot & & 3.5 .25 \\
\hline Kratky-Porodov lanac & Kratky-Porod chain & & 1.43. \\
\hline
\end{tabular}




\begin{tabular}{|c|c|c|c|}
\hline Hrvatski naziv (abecednim redom) & Engleski naziv & Simbol & $\begin{array}{l}\text { Broj } \\
\text { definicije }\end{array}$ \\
\hline kritična točka (u polimernoj znanosti) & critical point & & 3.3 .2 \\
\hline krivulja koegzistencije $^{n}$ & coexistence curve & & 3.3.3. \\
\hline krivulja zamagljenja & cloud point curve & & 3.3.8. \\
\hline kromatografija isključenjem po veličini & size-exclusion chromatography, SEC & & 3.6.6. \\
\hline kromatografija na propusnom gelu & gel-permeation chromatography, GPC & & 3.6.7. \\
\hline krutost lanca & chain stiffness & & 1.45. \\
\hline Kuhnov odsječak & Kuhn segment & & 1.37. \\
\hline \multicolumn{4}{|l|}{ Kuhnov segment $^{d} \rightarrow$ Kuhnov odsječak $^{p}$} \\
\hline kumulativna brojčana funkcija raspodjele & cumulative number-distribution function & $F_{\mathrm{n}}$ & 2.18. \\
\hline kumulativna brojčana raspodjela & cumulative number distribution & & 2.18 \\
\hline kumulativna funkcija raspodjele* & cumulative distribution function & & 2.16 \\
\hline kumulativna masena funkcija raspodjele & cumulative mass-distribution function & $F_{\mathrm{m},} F_{\mathrm{w}}$ & 2.20 \\
\hline kumulativna masena raspodjela & cumulative mass distribution & & 2.20 \\
\hline kumulativna raspodjela* & cumulative distribution & & 2.16 \\
\hline kut promatranja & angle of observation & & 3.5.11. \\
\hline kut raspršenja & scattering angle & $\theta$ & 3.5 .11 \\
\hline kvaliteta otapala & quality of solvent & & 3.2 .5 \\
\hline kvazielastično raspršenje svjetlosti & quasi-elastic light scattering, QELS & & 3.5.4. \\
\hline lanac (u polimernoj znanosti) & chain & & 1.3. \\
\hline logaritamska normalna raspodjela & logarithmic normal distribution & & 2.25 \\
\hline logaritamski viskoznosni broj $^{n}$ & logarithmic viscosity number & $\eta_{\ln }$ & 3.4.18. \\
\hline lognormalna raspodjela ${ }^{n}$ & log-normal distribution & & 2.25 \\
\hline makromolekulski isključeni volumen & macromolecular excluded volume & & 3.2.9. \\
\hline makromolekulsko klupko & macromolecular coil & & 1.40 \\
\hline mala čestica & small particle & & 3.5 .6$. \\
\hline mala molekula & small molecule & & 3.5.5. \\
\hline Mark-Houwink-Kuhn-Sakuradina jednadžba & Mark-Houwink-Kuhn-Sakurada equation & & 3.4 .24 \\
\hline Mark-Houwinkova jednadžba & Mark-Houwink equation & & 3.4.24. \\
\hline masena funkcija raspodjele & mass-distribution function & $f_{\mathrm{m}}, f_{\mathrm{w}}$ & 2.19 \\
\hline masena raspodjela & mass distribution & & 2.19 \\
\hline maseni prosjek molarne mase & mass-average molar-mass & $M_{\mathrm{m}}, M_{\mathrm{w}}$ & 2.9. \\
\hline maseni prosjek molekulske težine ${ }^{n}$ & mass-average molecular weight & $M_{r, m}, M_{r, w}$ & 2.9 . \\
\hline maseni prosjek relativne molarne mase & mass-average relative molar mass & $M_{\mathrm{r}, \mathrm{m}}$ & 2.9 . \\
\hline maseni prosjek relativne molekulske mase & mass-average relative molecular mass & $M_{\mathrm{r}, \mathrm{m}}$ & 2.9 \\
\hline međudjelovanje polimer-otapalo & polymer-solvent interaction & & 3.1.10. \\
\hline \multicolumn{4}{|l|}{$\begin{array}{l}\text { metoda brzine sedimentacije }{ }^{\mathrm{d}} \rightarrow \text { metoda brzine } \\
\text { taloženja }^{p}\end{array}$} \\
\hline metoda brzine taloženja ${ }^{p}$ & sedimentation-velocity method & & 3.4.11. \\
\hline \multicolumn{4}{|c|}{$\begin{array}{l}\text { metoda sedimentacijske ravnoteže } \mathrm{e}^{\mathrm{d}} \rightarrow \text { metoda taložne } \\
\text { ravnoteže }\end{array}$} \\
\hline metoda taložne ravnoteže ${ }^{p}$ & sedimentation-equilibrium method & & 3.4.10. \\
\hline Mieovo raspršenje (u polimernoj znanosti) & Mie scattering & & 3.5.10. \\
\hline mješljivost & miscibility & & 3.3.1. \\
\hline model ogrlice od perli & pearl-necklace model & & 3.4.35. \\
\hline model zrna i opruge & bead-spring model & & 3.4 .40 \\
\hline model zrna i štapića & bead-rod model & & 3.4.35. \\
\hline molalni prirast indeksa loma* & molal refractive index increment & & 3.5 .13 \\
\hline molarna masa & molar mass & $M$ & 2.5 \\
\hline molekulska težina $^{\mathrm{n}}$ & molecular weight & & 1.1. \\
\hline molekulski jednoliki polimer ${ }^{p}$ & molecularly uniform polymer & & 2.3. \\
\hline molekulski nejednoliki polimerp & molecularly non-uniforym polymer & & 2.4. \\
\hline $\begin{array}{l}\text { molekulski neuniformni polimer }{ }^{\mathrm{d}} \rightarrow \text { molekulski } \\
\text { nejednoliki polimer }\end{array}$ & & & \\
\hline
\end{tabular}




\begin{tabular}{|c|c|c|c|}
\hline Hrvatski naziv (abecednim redom) & Engleski naziv & Simbol & $\begin{array}{l}\text { Broj } \\
\text { definicije }\end{array}$ \\
\hline \multicolumn{4}{|l|}{$\begin{array}{l}\text { molekulski uniformni polimer }{ }^{d} \rightarrow \text { molekulski } \\
\text { jednoliki polimer }\end{array}$} \\
\hline monodisperzan* & monodisperse & & 2.3 \\
\hline najvjerojatnija raspodjela & most probable distribution & & 2.22 \\
\hline nasumce leteći lanac ${ }^{n}$ & random-flight chain & & 1.34. \\
\hline nasumce lutajući lanac ${ }^{n}$ & random-walk chain & & 1.34. \\
\hline neispresijecani slobodno povezani lanac & self-avoiding random-walk chain & & 1.39. \\
\hline nejednolik $k^{*}$ & non-uniform & & 2.3. \\
\hline nejednolika disperzija ${ }^{p}$ & non-uniform dispersion & & 3.5.2. \\
\hline nejednoliki polimerp & non-uniform polymer & & 2.4. \\
\hline neometana udaljenost krajeva & unperturbed end-to-end distance & $r_{\mathrm{o}}$ & 1.23. \\
\hline neometana udaljenost krajeva* & unperturbed end-to-end distance & & 1.26. \\
\hline neometane dimenzije & unperturbed dimensions & & 1.11. \\
\hline neometani polumjer vrtnje & unperturbed radius of gyration & $s_{\mathrm{o}}$ & 1.15. \\
\hline neometani vektor krajeva & unperturbed end-to-end vector & $\boldsymbol{r}_{\mathrm{o}}$ & 1.21 \\
\hline neometano konformacijsko stanje & unperturbed conformational state & & 1.12. \\
\hline nepropustan & impermeable, non-free-draining & & 3.4 .27 \\
\hline \multirow{3}{*}{\multicolumn{4}{|c|}{$\begin{array}{l}\text { neuniformna disperzija }{ }^{d} \rightarrow \text { nejednolika disperzija }^{p} \\
\text { neuniformni polimer }{ }^{d} \rightarrow \text { nejednoliki polimer }^{p} \\
\text { nukleacija faznog razdvajanja }{ }^{d} \rightarrow \text { jezgrenje faznog } \\
\text { razdvajanja }{ }^{p}\end{array}$}} \\
\hline & & & \\
\hline & & & \\
\hline obnavljanje cijevi & tube renewal & & 3.4 .45 \\
\hline \multicolumn{4}{|l|}{ obujam eluiranja $^{\mathrm{d}} \rightarrow$ volumen eluiranja $^{\mathrm{p}}$} \\
\hline \multicolumn{4}{|l|}{ obujam zadržavanja $^{\mathrm{d}} \rightarrow$ volumen zadržavanja $^{\mathrm{p}}$} \\
\hline odsječak lancap & chain segment & & 1.4. \\
\hline 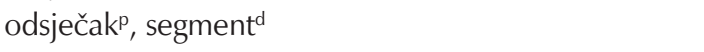 & segment & & 1.4. \\
\hline ometane dimenzije & perturbed dimensions & & 1.13. \\
\hline osmometar & osmometer & & 3.2.2. \\
\hline osmometrija & osmometry & & 3.2.3. \\
\hline osmotski tlak, $\Pi$ & osmotic pressure & & 3.2.1. \\
\hline osmotski virijalni koeficijent & osmotic virial coefficient & $A_{i}$ & 3.2.4. \\
\hline parametar topljivosti (polimera) & solubility parameter (of a polymer) & $\delta$ & 3.1 .14 \\
\hline Perrinova jednadžba & Perrin equation & & 3.4 .34 \\
\hline perzistencijska duljina & persistence length & a & 1.44. \\
\hline Poissonova raspodjela & Poisson distribution & & 2.23 \\
\hline polidisperzan* & polydisperse & & 2.3. \\
\hline polidisperznost ${ }^{*}$ & polydispersity & & 2.26. \\
\hline polumjer vrtnje & radius of gyration & $s$ & 1.14. \\
\hline polurazrijeđena otopina & semi-dilute solution & & 3.1.3. \\
\hline $\begin{array}{l}\text { poprečni presjek (kod raspršenja neutrona pri malim } \\
\text { kutovima) }\end{array}$ & cross-section & & 3.5 .15 \\
\hline pralanac & primitive chain & & 3.4 .46 \\
\hline \multicolumn{4}{|l|}{$\begin{array}{l}\text { precipitacijsko frakcioniranje }{ }^{d} \rightarrow \text { taložno } \\
\text { frakcioniranje }^{p}\end{array}$} \\
\hline preferirana sorpcija & preferential sorption & & 3.1.15. \\
\hline prepletaj (u polimernoj znanosti) & entanglement & & 3.1 .5 \\
\hline približavanje ravnoteži taloženja ${ }^{n^{*}}$ & approach to sedimentation equilibrium & & 3.4 .12 \\
\hline prijelazna koncentracija & cross-over concentration & $C^{*}$ & 3.1 .2$. \\
\hline prijenos količine gibanja ${ }^{p}$ & momentum transfer & & 3.5 .12$. \\
\hline \multicolumn{4}{|l|}{ prijenos momenta $^{d} \rightarrow$ prijenos količine gibanja $^{p}$} \\
\hline prirast indeksa loma & refractive index increment & $\partial n / \partial c$ & 3.5.13. \\
\hline prirast relativne viskoznosti & relative viscosity increment & $\eta_{\text {inc }}$ & 3.4.16. \\
\hline prividna molarna masa & apparent molar mass & $M_{\text {app }}$ & 2.13 \\
\hline prividna molekulska težina ${ }^{n}$ & apparent molecular-weight & $M_{\mathrm{r}, \mathrm{app}}$ & 2.13 \\
\hline
\end{tabular}




\begin{tabular}{|c|c|c|c|}
\hline Hrvatski naziv (abecednim redom) & Engleski naziv & Simbol & $\begin{array}{l}\text { Broj } \\
\text { definicije }\end{array}$ \\
\hline prividna relativna molarna masa & apparent relative-molar-mass & $M_{\text {r,app }}$ & 2.13 \\
\hline prividna relativna molekulska masa & apparent relative-molecular-mass & $M_{\mathrm{r}, \mathrm{app}}$ & 2.13 \\
\hline procjep u mješljivosti & miscibility gap & & 3.3.12. \\
\hline prosječni stupanj polimerizacije & average degree of polymerisation & $X_{k}$ & 2.15. \\
\hline prosjek molarne mase & molar-mass average & $M_{\mathrm{k}}$ & 2.7 \\
\hline prosjek molekulske težine $^{n}$ & molecular-weight average & $M_{\mathrm{r}, \mathrm{k}}$ & 2.7 \\
\hline prosjek relativne molarne mase & relative-molar-mass average & $M_{\mathrm{r}, \mathrm{k}}$ & 2.7 \\
\hline prosjek relativne molekulske mase & relative-molecular-mass average & $M_{r, k}$ & 2.7. \\
\hline raspodjela (u polimernoj znanosti) & distribution & & 2.16. \\
\hline raspršenje neutrona pri malim kutovima*, SANS & small-angle neutron scattering, SANS & & 3.5. Uvod \\
\hline $\begin{array}{l}\text { raspršenje rendgenskog zračenja pri malim kutovima*, } \\
\text { SAXS }\end{array}$ & small-angle X-ray scattering, SAXS & & 3.5. Uvod \\
\hline raspršenje svjetlosti*, LS & light scattering, LS & & 3.5. Uvod \\
\hline \multicolumn{4}{|l|}{ ravnoteža sedimentacije $^{\mathrm{d}} \rightarrow$ ravnoteža taloženja $^{\mathrm{p}}$} \\
\hline ravnoteža taloženjap & sedimentation equilibrium & & 3.4.9. \\
\hline \multicolumn{4}{|l|}{$\begin{array}{l}\text { ravnotežna sedimentacija u gradijentu gustoćé }{ }^{\mathrm{d}} \rightarrow \\
\text { ravnotežno taloženje u gradijentu gustoće }\end{array}$} \\
\hline \multicolumn{4}{|l|}{$\begin{array}{l}\text { ravnotežna sedimentacijska metoda }{ }^{\mathrm{d}} \rightarrow \text { ravnotežna } \\
\text { taložna metoda }\end{array}$} \\
\hline ravnotežna taložna metodap & equilibrium sedimentation method & & 3.4.10. \\
\hline ravnotežno taloženje u gradijentu gustoće ${ }^{p}$ & equilibrium sedimentation in a density gradient & & 3.4.13. \\
\hline Rayleighov omjer & Rayleigh ratio & $R(\theta), R_{\theta}$ & 3.5.15. \\
\hline Rayleighovo raspršenje & Rayleigh scattering & & 3.5.9. \\
\hline razrijeđena faza & dilute phase & & 3.6.2. \\
\hline razrijeđena otopina (u polimernoj znanosti) & dilute solution & & 3.1.1. \\
\hline reducirana viskoznost & reduced viscosity & & 3.4.17. \\
\hline relativna molarna masa & relative molar mass & $M_{\mathrm{r}}$ & 2.6. \\
\hline relativna molekulska masa & relative molecular mass & $M_{\mathrm{r}}$ & 1.1. \\
\hline relativna viskoznost & relative viscosity & $\eta_{\mathrm{r}}$ & 3.4.15. \\
\hline rotacijska difuzija & rotational diffusion & & 3.4.4. \\
\hline rotacijski difuzijski koeficijent & rotational diffusion coefficient & $\Theta$ & 3.4 .6$. \\
\hline rotacijski izomer & rotational isomer & & 1.8. \\
\hline rotacijski koeficijent trenja & rotational frictional coefficient & $\zeta$ & 3.4 .5 \\
\hline rotacijsko izomerno stanje (u polimernoj znanosti) & rotational isomeric state & & 1.9. \\
\hline rotamer & rotamer & & 1.8. \\
\hline Rouseov lanac & Rouse chain & & 3.4 .42$. \\
\hline Rouseova teorija & Rouse theory & & 3.4.41. \\
\hline Schulz-Floryjeva raspodjela & Schulz-Flory distribution & & 2.22 \\
\hline Schulz-Zimmova raspodjela & Schulz-Zimm distribution & & 2.21 \\
\hline \multicolumn{4}{|l|}{$\begin{array}{l}\text { sedimentacijska ravnoteža u gradijentu gustoće } e^{\mathrm{d}} \rightarrow \\
\text { taložna ravnoteža u gradijentu gustoće }\end{array}$} \\
\hline \multicolumn{4}{|l|}{ 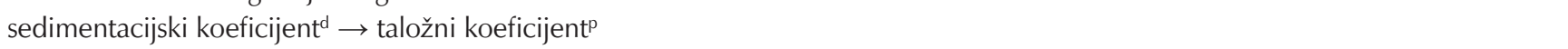 } \\
\hline \multicolumn{4}{|l|}{ segment lancad $\rightarrow$ odsječak lancap ${ }^{p}$} \\
\hline \multicolumn{4}{|l|}{ segment $^{\mathrm{d}} \rightarrow$ odsječak $^{\mathrm{p}}$} \\
\hline segmentni isključeni volumen & segmental excluded volume & & 3.2.8. \\
\hline selektivna sorpcija & selective sorption & & 3.1.15. \\
\hline selektivno otapalo & selective solvent & & 3.1.16. \\
\hline sinklinalni konformeri* & synclinal conformers & & 1.9. \\
\hline \multicolumn{4}{|l|}{ slobodni obujam ${ }^{d} \rightarrow$ slobodni volumen ${ }^{p}$} \\
\hline slobodni volumen ${ }^{p}$ & free volume & & 3.1.9. \\
\hline slobodno povezani lanac & freely jointed chain & & 1.34. \\
\hline slobodno propustan & free-draining, freely draining & & 3.4.26. \\
\hline slobodno rotirajuća udaljenost krajeva* & freely rotating end-to-end distance & & 1.30. \\
\hline slobodno rotirajući lanac & freely rotating chain & & 1.29 . \\
\hline
\end{tabular}




\begin{tabular}{|c|c|c|c|}
\hline Hrvatski naziv (abecednim redom) & Engleski naziv & Simbol & $\begin{array}{l}\text { Broj } \\
\text { definicije }\end{array}$ \\
\hline slučajno klupko & random coil & & 1.42 \\
\hline sol-faza ${ }^{n^{*}}$ & sol phase & & 3.6.2. \\
\hline specifična viskoznost ${ }^{* n}$ & specific viscosity & & 3.4.16. \\
\hline specifični prirast indeksa loma* & specific refractive index increment & & 3.5.13. \\
\hline spinodala & spinodal & & 3.3.4. \\
\hline spinodalna dekompozicija & spinodal decomposition & & 3.3.5. \\
\hline spinodalna krivulja & spinodal curve & & 3.3.4. \\
\hline spinodalno fazno razmješavanje & spinodal phase-demixing & & 3.3 .5$. \\
\hline srednji kvadrat neometane udaljenosti krajeva & mean-square unperturbed end-to-end distance & $\left\langle r_{\mathrm{o}}{ }^{2}\right\rangle$ & 1.27. \\
\hline srednji kvadrat neometanog polumjera vrtnje & mean-square unperturbed radius of gyration & $\left\langle\mathrm{s}_{\mathrm{o}}{ }^{2}\right\rangle$ & 1.19. \\
\hline srednji kvadrat polumjera vrtnje & mean-square radius of gyration & $\left\langle s^{2}\right\rangle$ & 1.17. \\
\hline srednji kvadrat udaljenosti krajeva & mean-square end-to-end distance & $\left\langle r^{2}\right\rangle$ & 1.25 \\
\hline $\begin{array}{l}\text { srednji kvadrat udaljenosti krajeva slobodno rotirajućeg } \\
\text { lanca }\end{array}$ & $\begin{array}{l}\text { mean-square end-to-end distance of a freely } \\
\text { rotating chain }\end{array}$ & $\left\langle r_{\mathrm{o}, \mathrm{f}}^{2}\right\rangle$ & 1.31. \\
\hline statički strukturni faktor & static structure factor & & 3.5.21. \\
\hline statičko raspršenje svjetlosti & static light scattering, SLS & & 3.5.3. \\
\hline statistički odsječak & statistical segment & & 1.37. \\
\hline \multicolumn{4}{|l|}{ statistički segment $^{d} \rightarrow$ statistički odsječak $^{p}$} \\
\hline statističko klupko & statistical coil & & 1.41. \\
\hline sterički faktor & steric factor & $\sigma$ & 1.32. \\
\hline Stokes-Einsteinova jednadžba & Stokes-Einstein equation & & 3.4 .33 \\
\hline Stokesova jednadžba & Stokes equation & & 3.4 .32 . \\
\hline stupanj polimerizacije (DP) & degree of polymerisation & $x$ & 1.2. \\
\hline sunetopljivost & co-nonsolvency & & 3.1.18. \\
\hline sutopljivost & co-solvency & & 3.1 .17 \\
\hline taložna ravnoteža u gradijentu gustoće ${ }^{p}$ & sedimentation equilibrium in a density gradient & & 3.4.13. \\
\hline taložni koeficijent ${ }^{p}$ & sedimentation coefficient & $s$ & 3.4.8. \\
\hline taložno frakcioniranje $\mathrm{p}^{\mathrm{p}}$ & precipitation fractionation & & 3.6.4. \\
\hline temperatura zamagljenja & cloud-point temperature & & 3.3.9. \\
\hline teorija usrednjenog polja & mean-field theory & & 3.1.11. \\
\hline termodinamička kvaliteta otapala & thermodynamic quality of solvent & & 3.2 .5 \\
\hline termodinamički ekvivalentna sfera & thermodynamically equivalent sphere & & 3.2.10. \\
\hline theta-stanje & theta state & & 3.2.6. \\
\hline theta-temperatura & theta temperature & $\theta$ & 3.2.7. \\
\hline točka zamagljenja & cloud point & & 3.3.7. \\
\hline translacijska difuzija & translational diffusion & & 3.4.1. \\
\hline translacijski difuzijski koeficijent & translational diffusion coefficient & $D$ & 3.4.3. \\
\hline translacijski koeficijent trenja & translational frictional coefficient & $f$ & 3.4 .2 \\
\hline Tungova raspodjela & Tung distribution & & 2.24 \\
\hline turbidimetrijska titracija & turbidimetric titration & & 3.5.19. \\
\hline \multicolumn{4}{|l|}{ turbidnost $^{d} \rightarrow$ zamućenost $^{p}$} \\
\hline udaljenost krajeva & end-to-end distance & $r$ & 1.22 \\
\hline udaljenost krajeva* & end-to-end distance & & 1.24. \\
\hline \multicolumn{4}{|l|}{ uniformna disperzija $^{\mathrm{d}} \rightarrow$ jednolika disperzija $^{p}$} \\
\hline \multicolumn{4}{|l|}{ uniformni polimer ${ }^{d} \rightarrow$ jednoliki polimer $^{p}$} \\
\hline \multicolumn{4}{|l|}{ univerzalna kalibracija $^{\mathrm{d}} \rightarrow$ univerzalno umjeravanje $^{\mathrm{p}}$} \\
\hline univerzalno umjeravanje $\mathrm{e}^{\mathrm{p}}$ & universal calibration & & 3.6.13. \\
\hline unutarmolekulska međudjelovanja dugog dosega & long-range intramolecular interaction & & 1.6. \\
\hline unutarmolekulska međudjelovanja kratkog dosega & short-range intramolecular interaction & & 1.5. \\
\hline uzao & blob & & 3.1.7. \\
\hline vektor krajeva & end-to-end vector & $r$ & 1.20. \\
\hline vektor raspršenja & scattering vector & $q$ & 3.5 .12 \\
\hline veličina očice $^{d} \rightarrow$ veličina oka mreže $^{p}$ & & & \\
\hline
\end{tabular}




\begin{tabular}{|c|c|c|c|}
\hline Hrvatski naziv (abecednim redom) & Engleski naziv & Simbol & $\begin{array}{l}\text { Broj } \\
\text { definicije }\end{array}$ \\
\hline veličina oka mreže ${ }^{p}$ & mesh size & $\xi$ & 3.1.6. \\
\hline velika čestica & large particle & & 3.5.8. \\
\hline velika molekula & large molecule & & 3.5.7. \\
\hline virijalni koeficijent kemijskog potencijala & virial coefficient of the chemical potential & & 3.2 .4 \\
\hline visina ekvivalentna teorijskom odsječku & height equivalent to a theoretical plate, HETP & & 3.6.16. \\
\hline visina teorijskog odsječka & plate height & $H$ & 3.6.16. \\
\hline viskoznosna funkcija & viscosity function & $\Phi$ & 3.4.39. \\
\hline viskoznosni broj $^{n}$ & viscosity number & & 3.4.17. \\
\hline viskoznosni faktor sažimanja & viscosity contraction factor & & 1.49. \\
\hline viskoznosni omjer $^{\mathrm{n}}$ & viscosity ratio & & 3.4.15. \\
\hline viskoznosni prosjek molarne mase & viscosity-average molar-mass & $M_{\mathrm{v}}$ & 2.12. \\
\hline viskoznosni prosjek molekulske težine ${ }^{n}$ & viscosity-average molecular weight & $M_{\mathrm{r}, \mathrm{v}}$ & 2.12 \\
\hline viskoznosni prosjek relativne molarne mase & viscosity-average relative molar mass & $M_{r, v}$ & 2.12. \\
\hline viskoznosni prosjek relativne molekulske mase & viscosity-average relative molecular mass & $M_{\mathrm{r}, \mathrm{v}}$ & 2.12 \\
\hline volumen eluiranja ${ }^{p}$ & elution volume & $V_{\mathrm{el}}$ & 3.6.10. \\
\hline volumen zadržavanja ${ }^{p}$ & retention volume & $V_{\mathrm{R}}$ & 3.6.12. \\
\hline vrijeme eluiranja & elution time & $t_{\mathrm{el}}$ & 3.6.9. \\
\hline vrijeme zadržavanja & retention time & $t_{\mathrm{R}}$ & 3.6.11. \\
\hline zakon sličnosti & scaling law & & 3.1.8. \\
\hline zamućenost ${ }^{p}$ & turbidity & $\tau$ & 3.5 .18 \\
\hline Zimmov dijagram & Zimm plot & & 3.5 .23 \\
\hline z-prosjek molarne mase & z-average molar-mass & $M_{z}$ & 2.10 \\
\hline z-prosjek molekulske težine ${ }^{n}$ & z-average molecular weight & $M_{\mathrm{r}, \mathrm{z}}$ & 2.10 \\
\hline z-prosjek relativne molarne mase & z-average relative molar mass & $M_{r, z}$ & 2.10 \\
\hline z-prosjek relativne molekulske mase & z-average relative molecular mass & $M_{\mathrm{r}, \mathrm{z}}$ & 2.10 \\
\hline$(z+1)$-prosjek molarne mase & $(z+1)$-average molar-mass & $M_{z+1}$ & 2.11 \\
\hline$(z+1)-$ prosjek molekulske težine ${ }^{n}$ & $(z+1)$-average molecular weight & $M_{r, z+1}$ & 2.11 \\
\hline$(z+1)$-prosjek relativne molarne mase & $(z+1)$-average relative molar mass & $M_{r, z+1}$ & 2.11 \\
\hline$(z+1)$-prosjek relativne molekulske mase & $(z+1)$-average relative molecular mass & $M_{r, z+1}$ & 2.11. \\
\hline$\theta$-stanje & $\theta$ state & & 3.2 .6 \\
\hline$\theta$-temperatura & $\theta$ temperature & & 3.2 .7 \\
\hline$\chi$-parametar & $\chi$ parameter & & 3.1 .13 \\
\hline 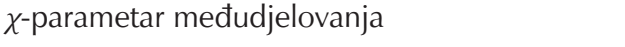 & $\chi$ interaction parameter & & 3.1 .13 \\
\hline
\end{tabular}

Tablica 2 - Engleski nazivi abecednim redom

\begin{tabular}{|c|c|c|c|}
\hline Engleski naziv & Hrvatski naziv (abecednim redom) & Simbol & $\begin{array}{l}\text { Broj } \\
\text { definicije }\end{array}$ \\
\hline angle of observation & kut promatranja & & 3.5 .11 \\
\hline antiperiplanar conformers & antiperiplanarni konformeri* & & 1.9. \\
\hline apparent molar mass & prividna molarna masa & $M_{\text {app }}$ & 2.13. \\
\hline apparent molecular-weight & prividna molekulska težina ${ }^{n}$ & $M_{\mathrm{r}, \mathrm{app}}$ & 2.13. \\
\hline apparent relative-molar-mass & prividna relativna molarna masa & $M_{\mathrm{r}, \mathrm{app}}$ & 2.13 \\
\hline apparent relative-molecular-mass & prividna relativna molekulska masa & $M_{\mathrm{r}, \mathrm{app}}$ & 2.13. \\
\hline approach to sedimentation equilibrium & približavanje ravnoteži taloženja ${ }^{n^{*}}$ & & 3.4 .12$. \\
\hline Archibald's method & Archibaldova metoda & & 3.4 .12$. \\
\hline average degree of polymerisation & prosječni stupanj polimerizacije & $X_{k}$ & 2.15 \\
\hline bead-rod model & model zrna i štapića & & 3.4 .35$. \\
\hline bead-spring model & model zrna i opruge & & 3.4 .40 \\
\hline binodal & binodala (u polimernoj znanosti) & & 3.3.3. \\
\hline binodal curve & binodalna krivulja & & 3.3.3. \\
\hline blob & uzao & & 3.1.7. \\
\hline
\end{tabular}




\begin{tabular}{|c|c|c|c|}
\hline Engleski naziv & Hrvatski naziv (abecednim redom) & Simbol & $\begin{array}{l}\text { Broj } \\
\text { definicije }\end{array}$ \\
\hline bond-conformational state & konformacijsko stanje veze (u polimernoj znanosti) & & 1.9. \\
\hline chain & lanac (u polimernoj znanosti) & & 1.3. \\
\hline chain conformation & konformacija lanca & & 1.10. \\
\hline chain expansion factor & faktor ekspanzije lanca & & 3.2.11. \\
\hline chain segment & odsječak lancap , segment lanca ${ }^{d}$ & & 1.4. \\
\hline chain stiffness & krutost lanca & & 1.45. \\
\hline characteristic ratio & karakteristični omjer & $\begin{array}{l}C_{n}\left(C_{\infty} \text { kad }\right. \\
n \rightarrow \infty)\end{array}$ & 1.28. \\
\hline chi interaction parameter & hi-parametar međudjelovanja & & 3.1.13. \\
\hline chi parameter & hi-parametar & $\chi$ & 3.1.13. \\
\hline cloud point & točka zamagljenja & & 3.3.7. \\
\hline cloud point curve & krivulja zamagljenja & & 3.3.8. \\
\hline cloud-point temperature & temperatura zamagljenja & & 3.3 .9 \\
\hline coexistence curve & krivulja koegzistencijen & & 3.3.3. \\
\hline compositional heterogeneity & heterogenost sastava & & 2.1. \\
\hline concentrated phase & koncentrirana faza & & 3.6.3. \\
\hline concentrated solution & koncentrirana otopina & & 3.1 .4 \\
\hline conformer & konformer & & 1.7. \\
\hline co-nonsolvency & sunetopljivost & & 3.1.18. \\
\hline constitutional heterogeneity & konstitucijska heterogenost & & 2.2. \\
\hline contour length & duljina konture & $r_{\max }$ & 1.35. \\
\hline contraction factor & faktor sažimanja & & 1.48. \\
\hline co-solvency & sutopljivost & & 3.1.17. \\
\hline critical point & kritična točka (u polimernoj znanosti) & & 3.3.2. \\
\hline cross-over concentration & prijelazna koncentracija & $c^{*}$ & 3.1 .2$. \\
\hline cross-section & $\begin{array}{l}\text { poprečni presjek (kod raspršenja neutrona pri malim } \\
\text { kutovima) }\end{array}$ & & 3.5.15. \\
\hline cumulative distribution & kumulativna raspodjela* & & 2.16 . \\
\hline cumulative distribution function & kumulativna funkcija raspodjele* & & 2.16. \\
\hline cumulative mass distribution & kumulativna masena raspodjela & & 2.20 . \\
\hline cumulative mass-distribution function & kumulativna masena funkcija raspodjele & $F_{\mathrm{m},} F_{\mathrm{w}}$ & 2.20 . \\
\hline cumulative number distribution & kumulativna brojčana raspodjela & & 2.18. \\
\hline cumulative number-distribution function & kumulativna brojčana funkcija raspodjele & $F_{\mathrm{n}}$ & 2.18. \\
\hline degree of polymerisation & stupanj polimerizacije (DP) & $x$ & 1.2. \\
\hline degree-of-polymerisation dispersity & disperznost stupnja polimerizacije & $\bigoplus_{x}$ & 2.27 \\
\hline depolarization of scattered light & depolarizacija raspršenog svjetla & & 3.5.27. \\
\hline differential distribution & diferencijalna raspodjela* & & 2.16. \\
\hline differential distribution function & diferencijalna funkcija raspodjele* & & 2.16. \\
\hline differential mass distribution & diferencijalna masena raspodjela & & 2.19 . \\
\hline differential mass-distribution function & diferencijalna masena funkcija raspodjele & & 2.19 . \\
\hline differential number distribution & diferencijalna brojčana raspodjela & & 2.17 \\
\hline differential number-distribution function & diferencijalna brojčana funkcija raspodjele & & 2.17 \\
\hline diffusion coefficient & difuzijski koeficijent & & 3.4.3. \\
\hline dilute phase & razrijeđena faza & & 3.6 .2 . \\
\hline dilute solution & razrijeđena otopina (u polimernoj znanosti) & & 3.1 .1 \\
\hline dispersity & disperznost & $\bigoplus$ & 2.28. \\
\hline dissymmetry of scattering & disimetrija raspršenja & $z\left(\theta_{1}, \theta_{2}\right)$ & 3.5 .26 . \\
\hline distribution & raspodjela (u polimernoj znanosti) & & 2.16. \\
\hline distribution function & funkcija raspodjele (u polimernoj znanosti) & & 2.16. \\
\hline dynamic light scattering, DLS & dinamičko raspršenje svjetlosti & & 3.5.4. \\
\hline dynamic structure factor & dinamički strukturni faktor & & 3.5 .22 . \\
\hline effective bond length & efektivna duljina veze & $b$ & 1.33. \\
\hline elution time & vrijeme eluiranja & $t_{\mathrm{el}}$ & 3.6 .9$. \\
\hline
\end{tabular}




\begin{tabular}{|c|c|c|c|}
\hline Engleski naziv & Hrvatski naziv (abecednim redom) & Simbol & $\begin{array}{l}\text { Broj } \\
\text { definicije }\end{array}$ \\
\hline elution volume & volumen eluiranja ${ }^{p}$, obujam eluiranja ${ }^{d}$ & $V_{\text {el }}$ & 3.6 .10 \\
\hline end-to-end distance & udaljenost krajeva & $r$ & 1.22. \\
\hline end-to-end distance & udaljenost krajeva* & & 1.24 \\
\hline end-to-end vector & vektor krajeva & $r$ & 1.20 \\
\hline entanglement & prepletaj (u polimernoj znanosti) & & 3.1 .5 \\
\hline equilibrium sedimentation in a density gradient & $\begin{array}{l}\text { ravnotežno taloženje u gradijentu gustoće }{ }^{p}, \\
\text { ravnotežna sedimentacija u gradijentu gustoće }^{d}\end{array}$ & & 3.4.13. \\
\hline equilibrium sedimentation method & $\begin{array}{l}\text { ravnotežna taložna metoda }{ }^{p}, \text { ravnotežna } \\
\text { sedimentacijska metoda }^{\mathrm{d}}\end{array}$ & & 3.4 .10 \\
\hline equivalent freely jointed chain & ekvivalentni slobodno povezani lanac & & 1.36. \\
\hline equivalent freely jointed link & ekvivalentna slobodna poveznican & & 1.37. \\
\hline equivalent hydrodynamic radius & ekvivalentni hidrodinamički polumjer & & 3.4 .31 \\
\hline equivalent hydrodynamic volume & ekvivalentni hidrodinamički volumen & & 3.4 .30 \\
\hline excess Rayleigh ratio & ekscesni Rayleighov omjer & $\Delta R(\theta), \Delta R_{\theta}$ & 3.5 .16 \\
\hline excess scattering & ekscesno raspršenje & & 3.5 .17 \\
\hline excluded volume of a macromolecule & isključeni volumen makromolekule & & 3.2.9. \\
\hline excluded volume of a segment & isključeni volumen segmenta & & 3.2.8. \\
\hline expansion factor & ekspanzijski faktor & $\alpha_{r}, \alpha_{s}, \alpha_{D}, \alpha_{\eta}$ & 3.2.11. \\
\hline extraction fractionation & ekstrakcijsko frakcioniranje & & 3.6 .5 \\
\hline Flory distribution & Floryjeva raspodjela & & 2.22 \\
\hline Flory function & Floryjeva funkcija & & 3.4.39. \\
\hline Flory-Fox assumption & Flory-Foxova pretpostavka & & 3.4 .37 \\
\hline Flory-Fox equation & Flory-Foxova jednadžba & & 3.4.38. \\
\hline Flory-Huggins theory & Flory-Hugginsova teorija & & 3.1 .12 \\
\hline Flory-Huggins-Staverman theory & Flory-Huggins-Stavermanova teorija & & 3.1 .12$. \\
\hline flow birefringence & birefringencija strujanja $^{n}$ & & 3.4 .7 \\
\hline form factor & faktor oblika & & 3.5 .20 \\
\hline fractional precipitation & frakcijsko taloženje ${ }^{p}$, frakcijska precipitacija ${ }^{n}$ & & 3.6.4. \\
\hline fractionation & frakcioniranje & & 3.6.1. \\
\hline free volume & slobodni volumen ${ }^{\mathrm{p}}$, slobodni obujam ${ }^{\mathrm{d}}$ & & 3.1.9. \\
\hline free-draining, freely draining & slobodno propustan & & 3.4 .26 \\
\hline freely jointed chain & slobodno povezani lanac & & 1.34. \\
\hline freely jointed link length & duljina ekvivalentne slobodne poveznice ${ }^{n}$ & & 1.38. \\
\hline freely rotating chain & slobodno rotirajući lanac & & 1.29. \\
\hline freely rotating end-to-end distance & slobodno rotirajuća udaljenost krajeva* & & 1.30. \\
\hline frictional coefficient & koeficijent trenja & & 3.4.2. \\
\hline fully extended chain length & duljina potpuno ispruženog lanca & & 1.35. \\
\hline$g^{\prime}$-factor & $g^{\prime}$-faktor & $g^{\prime}$ & 1.49. \\
\hline Gaussian coil & Gaussovo klupko & & 1.42. \\
\hline gel phase & gel-faza ${ }^{n^{*}}$ & & 3.6.3. \\
\hline gel-permeation chromatography, GPC & kromatografija na propusnom gelu & & 3.6.7. \\
\hline geometric contraction factor & geometrijski faktor sažimanja & & 1.48. \\
\hline$g$-factor & $g$-faktor & $g$ & 1.48. \\
\hline Guinier plot & Guinierov dijagram & & 3.5.24. \\
\hline height equivalent to a theoretical plate, HETP & visina ekvivalentna teorijskom odsječku & & 3.6 .16 \\
\hline Huggins coefficient & Hugginsov koeficijent & $k_{\mathrm{H}}$ & 3.4.21. \\
\hline Huggins equation & Hugginsova jednadžba & & 3.4 .20 \\
\hline hydrodynamic contraction factor & hidrodinamički faktor sažimanja & & 1.49. \\
\hline hydrodynamic interaction & hidrodinamičko međudjelovanje & & 3.4 .25 \\
\hline hydrodynamically equivalent sphere & hidrodinamički ekvivalentna kugla & & 3.4.29. \\
\hline impermeable, non-free-draining & nepropustan & & 3.4 .27 \\
\hline inherent viscosity & inherentna viskoznost & $\eta_{\text {inh }}$ & 3.4.18. \\
\hline integral distribution & integralna raspodjela* & & 2.16. \\
\hline
\end{tabular}




\begin{tabular}{|c|c|c|c|}
\hline Engleski naziv & Hrvatski naziv (abecednim redom) & Simbol & $\begin{array}{l}\text { Broj } \\
\text { definicije }\end{array}$ \\
\hline integral distribution function & integralna funkcija raspodjele* & & 2.16 \\
\hline integral mass distribution & integralna masena raspodjela & & 2.20 \\
\hline integral mass-distribution function & integralna masena funkcija raspodjele & & 2.20 \\
\hline integral number distribution & integralna brojčana raspodjela & & 2.18. \\
\hline integral number-distribution function & integralna brojčana funkcija raspodjele & & 2.18. \\
\hline intrinsic viscosity & intrinzična viskoznost & {$[\eta]$} & 3.4.19. \\
\hline isopycnic & izopiknički & & 3.4 .14 \\
\hline isorefractive & izorefrakcijski & & 3.5 .14 \\
\hline Kirkwood-Riseman theory & Kirkwood-Risemanova teorija & & 3.4 .36 . \\
\hline Kraemer coefficient & Kraemerov koeficijent & $k_{\mathrm{K}}$ & 3.4 .23 . \\
\hline Kraemer equation & Kraemerova jednadžba & & 3.4 .22 . \\
\hline Kratky plot & Kratkyjev dijagram & & 3.5 .25 \\
\hline Kratky-Porod chain & Kratky-Porodov lanac & & 1.43. \\
\hline Kuhn segment & Kuhnov odsječakp ${ }^{p}$ Kuhnov segment ${ }^{d}$ & & 1.37. \\
\hline Kuhn segment length & duljina Kuhnova segmenta & $I^{\prime}, I_{\mathrm{K}}$ & 1.38. \\
\hline large molecule & velika molekula & & 3.5.7. \\
\hline large particle & velika čestica & & 3.5.8. \\
\hline light scattering, LS & raspršenje svjetlosti", LS & & 3.5. Uvod \\
\hline limiting viscosity number & 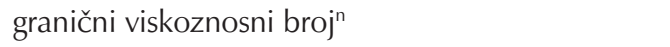 & & 3.4.19. \\
\hline logarithmic normal distribution & logaritamska normalna raspodjela & & 2.25 . \\
\hline logarithmic viscosity number & logaritamski viskoznosni broj ${ }^{\text {n }}$ & $\eta_{\mathrm{ln}}$ & 3.4.18. \\
\hline log-normal distribution & lognormalna raspodjela ${ }^{n}$ & & 2.25 \\
\hline long-chain branch & dugolančana grana & & 1.47. \\
\hline long-range intramolecular interaction & unutarmolekulska međudjelovanja dugog dosega & & 1.6. \\
\hline lower critical solution temperature, LCST & donja kritična temperatura otopine, DKTO & & 3.3.10. \\
\hline macromolecular coil & makromolekulsko klupko & & 1.40. \\
\hline macromolecular excluded volume & makromolekulski isključeni volumen & & 3.2.9. \\
\hline Mark-Houwink equation & Mark-Houwinkova jednadžba & & 3.4.24. \\
\hline Mark-Houwink-Kuhn-Sakurada equation & Mark-Houwink-Kuhn-Sakuradina jednadžba & & 3.4 .24 \\
\hline mass distribution & masena raspodjela & & 2.19. \\
\hline mass-average molar-mass & maseni prosjek molarne mase & $M_{\mathrm{m}}, M_{\mathrm{w}}$ & 2.9. \\
\hline mass-average molecular weight & maseni prosjek molekulske težine ${ }^{n}$ & $M_{r, m}, M_{r, w}$ & 2.9 . \\
\hline mass-average relative molar mass & maseni prosjek relativne molarne mase & $M_{\mathrm{r}, \mathrm{m}}$ & 2.9 . \\
\hline mass-average relative molecular mass & maseni prosjek relativne molekulske mase & $M_{\mathrm{r}, \mathrm{m}}$ & 2.9. \\
\hline mass-distribution function & masena funkcija raspodjele & $f_{\mathrm{m}}, f_{\mathrm{w}}$ & 2.19. \\
\hline mean-field theory & teorija usrednjenog polja & & 3.1.11. \\
\hline mean-square end-to-end distance & srednji kvadrat udaljenosti krajeva & $\left\langle r^{2}\right\rangle$ & 1.25 \\
\hline $\begin{array}{l}\text { mean-square end-to-end distance of a freely } \\
\text { rotating chain }\end{array}$ & $\begin{array}{l}\text { srednji kvadrat udaljenosti krajeva slobodno } \\
\text { rotirajućeg lanca }\end{array}$ & $\left\langle r_{\mathrm{o}, \mathrm{f}}^{2}\right\rangle$ & 1.31. \\
\hline mean-square radius of gyration & srednji kvadrat polumjera vrtnje & $\left\langle s^{2}\right\rangle$ & 1.17. \\
\hline mean-square unperturbed end-to-end distance & srednji kvadrat neometane udaljenosti krajeva & $\left\langle r_{\mathrm{o}}^{2}\right\rangle$ & 1.27 \\
\hline mean-square unperturbed radius of gyration & srednji kvadrat neometanog polumjera vrtnje & $\left\langle s_{\mathrm{o}}{ }^{2}\right\rangle$ & 1.19. \\
\hline mesh size & veličina oka mreže ${ }^{p}$, veličina očice ${ }^{d}$ & $\xi$ & 3.1.6. \\
\hline Mie scattering & Mieovo raspršenje (u polimernoj znanosti) & & 3.5.10. \\
\hline miscibility & mješljivost & & 3.3.1. \\
\hline miscibility gap & procjep u mješljivosti & & 3.3 .12 \\
\hline molal refractive index increment & molalni prirast indeksa loma* & & 3.5.13. \\
\hline molar mass & molarna masa & M & 2.5 \\
\hline molar-mass average & prosjek molarne mase & $M_{\mathrm{k}}$ & 2.7. \\
\hline molar-mass dispersity & disperznost molarne mase & $\bigoplus_{M}$ & 2.26. \\
\hline molar-mass exclusion limit & granica isključenja molarne mase & & 3.6.8. \\
\hline molecular weight & molekulska težina $^{\mathrm{n}}$ & & 1.1. \\
\hline molecularly non-uniforym polymer & $\begin{array}{l}\text { molekulski nejednoliki polimerp, molekulski } \\
\text { neuniformni polimer }{ }^{\mathrm{d}}\end{array}$ & & 2.4 \\
\hline
\end{tabular}




\begin{tabular}{|c|c|c|c|}
\hline Engleski naziv & Hrvatski naziv (abecednim redom) & Simbol & $\begin{array}{l}\text { Broj } \\
\text { definicije }\end{array}$ \\
\hline molecularly uniform polymer & $\begin{array}{l}\text { molekulski jednoliki polimerp, molekulski uniformni } \\
\text { polimer }^{d}\end{array}$ & & 2.3. \\
\hline molecular-weight average & prosjek molekulske težine ${ }^{n}$ & $M_{r, k}$ & 2.7 \\
\hline molecular-weight dispersity & disperznost molekulske težine ${ }^{n}$ & & 2.26. \\
\hline molecular-weight exclusion limit & granica isključenja molekulske težine ${ }^{n}$ & & 3.6.8. \\
\hline momentum transfer & prijenos momenta, prijenos količine gibanja & & 3.5.12. \\
\hline monodisperse & monodisperzan* & & 2.3. \\
\hline most probable distribution & najvjerojatnija raspodjela & & 2.22. \\
\hline non-uniform & nejednolik* & & 2.3. \\
\hline non-uniform dispersion & nejednolika disperzijap, neuniformna disperzija ${ }^{d}$ & & 3.5 .2$. \\
\hline non-uniform polymer & nejednoliki polimerp, neuniformni polimer ${ }^{d}$ & & 2.4. \\
\hline nucleation & jezgrenje* $^{*}$ & & 3.3.6. \\
\hline nucleation of phase separation & $\begin{array}{l}\text { jezgrenje faznog razdvajanjap }{ }^{p} \text {, nukleacija faznog } \\
\text { razdvajanja }^{d}\end{array}$ & & 3.3.6. \\
\hline number distribution & brojčana raspodjela & & 2.17 \\
\hline number-average molar-mass & brojčani prosjek molarne mase & $M_{\mathrm{n}}$ & 2.8. \\
\hline number-average molecular weight & brojčani prosjek molekulske težine ${ }^{\mathrm{n}}$ & $M_{\mathrm{r}, \mathrm{n}}$ & 2.8 . \\
\hline number-average relative molar mass & brojčani prosjek relativne molarne mase & $M_{\mathrm{r}, \mathrm{n}}$ & 2.8 . \\
\hline number-average relative molecular mass & brojčani prosjek relativne molekulske mase & $M_{\mathrm{r}, \mathrm{n}}$ & 2.8. \\
\hline number-distribution function & brojčana funkcija raspodjele & $f_{\mathrm{n}}$ & 2.17 \\
\hline osmometer & osmometar & & 3.2 .2 \\
\hline osmometry & osmometrija & & 3.2 .3 \\
\hline osmotic pressure & osmotski tlak, $\Pi$ & & 3.2 .1 \\
\hline osmotic virial coefficient & osmotski virijalni koeficijent & $A_{i}$ & 3.2 .4 \\
\hline overlap concentration & koncentracija preklapanjan & & 3.1.2. \\
\hline partial free-draining, partially draining & djelomično propustan & & 3.4.28. \\
\hline particle scattering factor & čestični faktor raspršenja & & 3.5.20. \\
\hline particle scattering function & čestična funkcija raspršenja & $P(\theta), P_{\theta}$ & 3.5.20. \\
\hline pearl-necklace model & model ogrlice od perli & & 3.4.35. \\
\hline Perrin equation & Perrinova jednadžba & & 3.4.34. \\
\hline persistence length & perzistencijska duljina & a & 1.44. \\
\hline perturbed dimensions & ometane dimenzije & & 1.13. \\
\hline photon-correlation spectroscopy, PCS & fotonska korelacijska spektroskopija & & 3.5.4. \\
\hline plate height & visina teorijskog odsječka & $H$ & 3.6.16. \\
\hline plate number & broj teorijskih odsječaka & $N$ & 3.6.15. \\
\hline Poisson distribution & Poissonova raspodjela & & 2.23. \\
\hline polydisperse & polidisperzan* & & 2.3. \\
\hline polydispersity & polidisperznost ${ }^{*}$ & & 2.26 \\
\hline polydispersity index & indeks polidisperznosti* & & 2.26 \\
\hline polymer-poor phase & faza siromašna polimerom & & 3.6 .2 . \\
\hline polymer-rich phase & faza bogata polimerom & & 3.6.3. \\
\hline polymer-solvent interaction & međudjelovanje polimer-otapalo & & 3.1.10. \\
\hline polymolecularity correction & korekcija zbog polimolekularnosti & & 2.14 \\
\hline precipitation fractionation & $\begin{array}{l}\text { taložno frakcioniranjep } \mathrm{p}^{\mathrm{p}} \text {, precipitacijsko } \\
\text { frakcioniranje }^{\mathrm{d}}\end{array}$ & & 3.6.4. \\
\hline preferential sorption & preferirana sorpcija & & 3.1.15. \\
\hline primitive chain & pralanac & & 3.4 .46 . \\
\hline probability density function & funkcija gustoće vjerojatnosti* & & 2.16 \\
\hline quality of solvent & kvaliteta otapala & & 3.2.5. \\
\hline quasi-elastic light scattering, QELS & kvazielastično raspršenje svjetlosti & & 3.5.4. \\
\hline radius of gyration & polumjer vrtnje & $s$ & 1.14. \\
\hline radius of gyration contraction factor & faktor sažimanja polumjera vrtnje & & 1.48. \\
\hline random coil & slučajno klupko & & 1.42. \\
\hline random-flight chain & nasumce leteći lanac ${ }^{n}$ & & 1.34. \\
\hline
\end{tabular}




\begin{tabular}{|c|c|c|c|}
\hline Engleski naziv & Hrvatski naziv (abecednim redom) & Simbol & $\begin{array}{l}\text { Broj } \\
\text { definicije }\end{array}$ \\
\hline random-walk chain & nasumce lutajući lanac ${ }^{n}$ & & 1.34 \\
\hline Rayleigh ratio & Rayleighov omjer & $R(\theta), R_{\theta}$ & 3.5.15. \\
\hline Rayleigh scattering & Rayleighovo raspršenje & & 3.5.9. \\
\hline reduced viscosity & reducirana viskoznost & & 3.4.17. \\
\hline refractive index increment & prirast indeksa loma & $\partial n / \partial c$ & 3.5.13. \\
\hline relative molar mass & relativna molarna masa & $M_{\mathrm{r}}$ & 2.6. \\
\hline relative molecular mass & relativna molekulska masa & $M_{\mathrm{r}}$ & 1.1. \\
\hline relative viscosity & relativna viskoznost & $\eta_{\mathrm{r}}$ & 3.4.15. \\
\hline relative viscosity increment & prirast relativne viskoznosti & $\eta_{\text {inc }}$ & 3.4.16. \\
\hline relative-molar-mass average & prosjek relativne molarne mase & $M_{r, k}$ & 2.7. \\
\hline relative-molar-mass dispersity & disperznost relativne molarne mase & & 2.26. \\
\hline relative-molecular-mass average & prosjek relativne molekulske mase & $M_{r, k}$ & 2.7 \\
\hline relative-molecular-mass dispersity & disperznost relativne molekulske mase & & 2.26 \\
\hline reptation & gmizanje & & 3.4.43. \\
\hline retention time & vrijeme zadržavanja & $t_{\mathrm{R}}$ & 3.6.11. \\
\hline retention volume & volumen zadržavanjap $^{p}$, obujam zadržavanjad & $V_{R}$ & 3.6.12. \\
\hline root-mean-square end-to-end distance & korijen srednjeg kvadrata udaljenosti krajeva & $\left\langle r^{2}\right\rangle^{1 / 2}$ & 1.24. \\
\hline $\begin{array}{l}\text { root-mean-square end-to-end distance of a freely } \\
\text { rotating chain }\end{array}$ & $\begin{array}{l}\text { korijen srednjeg kvadrata udaljenosti krajeva } \\
\text { slobodno rotirajućeg lanca }\end{array}$ & $\left\langle r_{0, f^{2}}^{2}\right\rangle^{1 / 2}$ & 1.30. \\
\hline root-mean-square radius of gyration & korijen srednjeg kvadrata polumjera vrtnje & $\left\langle\mathrm{s}^{2}\right\rangle^{1 / 2}, R_{\mathrm{g}}$ & 1.16. \\
\hline $\begin{array}{l}\text { root-mean-square unperturbed end-to-end } \\
\text { distance }\end{array}$ & $\begin{array}{l}\text { korijen srednjeg kvadrata neometane udaljenosti } \\
\text { krajeva }\end{array}$ & $\left\langle r_{\mathrm{o}}{ }^{2}\right\rangle^{1 / 2}$ & 1.26 \\
\hline root-mean-square unperturbed radius of gyration & $\begin{array}{l}\text { korijen srednjeg kvadrata neometanog polumjera } \\
\text { vrtnje }\end{array}$ & $\left\langle s_{0}{ }^{2}\right\rangle^{1 / 2}$ & 1.18. \\
\hline rotamer & rotamer & & 1.8. \\
\hline rotational diffusion & rotacijska difuzija & & 3.4 .4 \\
\hline rotational diffusion coefficient & rotacijski difuzijski koeficijent & $\Theta$ & 3.4 .6$. \\
\hline rotational frictional coefficient & rotacijski koeficijent trenja & $\zeta$ & 3.4.5. \\
\hline rotational isomer & rotacijski izomer & & 1.8. \\
\hline rotational isomeric state & rotacijsko izomerno stanje (u polimernoj znanosti) & & 1.9. \\
\hline Rouse chain & Rouseov lanac & & 3.4 .42 \\
\hline Rouse theory & Rouseova teorija & & 3.4.41. \\
\hline scaling law & zakon sličnosti & & 3.1 .8 \\
\hline scattering angle & kut raspršenja & $\theta$ & 3.5.11. \\
\hline scattering vector & vektor raspršenja & $q$ & 3.5.12. \\
\hline Schulz-Flory distribution & Schulz-Floryjeva raspodjela & & 2.22 \\
\hline Schulz-Zimm distribution & Schulz-Zimmova raspodjela & & 2.21 \\
\hline sedimentation coefficient & taložni koeficijentp ${ }^{p}$, sedimentacijski koeficijent ${ }^{d}$ & s & 3.4 .8$. \\
\hline sedimentation equilibrium & 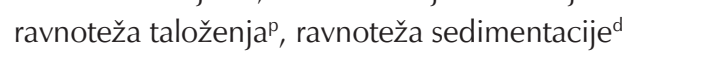 & & 3.4.9. \\
\hline sedimentation equilibrium in a density gradient & $\begin{array}{l}\text { taložna ravnoteža u gradijentu gustoćep, } \\
\text { sedimentacijska ravnoteža u gradijentu gustoće }\end{array}$ & & 3.4.13. \\
\hline sedimentation-equilibrium method & $\begin{array}{l}\text { metoda taložne ravnotežep }{ }^{p} \text { metoda sedimentacijske } \\
\text { ravnoteže } e^{d}\end{array}$ & & 3.4.10. \\
\hline sedimentation-velocity method & $\begin{array}{l}\text { metoda brzine taloženja }{ }^{p} \text {, metoda brzine } \\
\text { sedimentacije }\end{array}$ & & 3.4.11. \\
\hline segment & odsječak $^{p}$, segment ${ }^{d}$ & & 1.4. \\
\hline segmental excluded volume & segmentni isključeni volumen & & 3.2.8. \\
\hline selective solvent & selektivno otapalo & & 3.1.16. \\
\hline selective sorption & selektivna sorpcija & & 3.1.15. \\
\hline self-avoiding random-walk chain & neispresijecani slobodno povezani lanac & & 1.39. \\
\hline semi-dilute solution & polurazrijeđena otopina & & 3.1.3. \\
\hline short-chain branch & kratkolančana grana & & 1.46. \\
\hline short-range intramolecular interaction & unutarmolekulska međudjelovanja kratkog dosega & & 1.5. \\
\hline size-exclusion chromatography, SEC & kromatografija isključenjem po veličini & & 3.6.6. \\
\hline
\end{tabular}




\begin{tabular}{|c|c|c|c|}
\hline Engleski naziv & Hrvatski naziv (abecednim redom) & Simbol & $\begin{array}{l}\text { Broj } \\
\text { definicije }\end{array}$ \\
\hline small molecule & mala molekula & & 3.5.5. \\
\hline small particle & mala čestica & & 3.5.6. \\
\hline small-angle neutron scattering, SANS & raspršenje neutrona pri malim kutovima*, SANS & & 3.5. Uvod \\
\hline small-angle X-ray scattering, SAXS & $\begin{array}{l}\text { raspršenje rendgenskog zračenja pri malim } \\
\text { kutovima*, SAXS }\end{array}$ & & 3.5. Uvod \\
\hline sol phase & sol-faza $\mathrm{n}^{n^{*}}$ & & 3.6.2. \\
\hline solubility parameter (of a polymer) & parametar topljivosti (polimera) & $\delta$ & 3.1.14. \\
\hline specific refractive index increment & specifični prirast indeksa loma* & & 3.5.13. \\
\hline specific viscosity & specifična viskoznost $^{* n}$ & & 3.4.16. \\
\hline spinodal & spinodala & & 3.3.4. \\
\hline spinodal curve & spinodalna krivulja & & 3.3.4. \\
\hline spinodal decomposition & spinodalna dekompozicija & & 3.3.5. \\
\hline spinodal phase-demixing & spinodalno fazno razmješavanje & & 3.3.5. \\
\hline spreading function & funkcija širenja & & 3.6.14. \\
\hline static light scattering, SLS & statičko raspršenje svjetlosti & & 3.5.3. \\
\hline static structure factor & statički strukturni faktor & & 3.5.21. \\
\hline statistical coil & statističko klupko & & 1.41. \\
\hline statistical segment & statistički odsječak ${ }^{\mathrm{p}}$, statistički segment ${ }^{\mathrm{d}}$ & & 1.37. \\
\hline statistical segment length & duljina statističkog segmenta & & 1.38. \\
\hline steric factor & sterički faktor & $\sigma$ & 1.32. \\
\hline Stokes equation & Stokesova jednadžba & & 3.4.32. \\
\hline Stokes-Einstein equation & Stokes-Einsteinova jednadžba & & 3.4.33. \\
\hline streaming birefringence & dvolom pri strujanju kapljevinap ${ }^{p}$ & & 3.4.7. \\
\hline synclinal conformers & sinklinalni konformeri* & & 1.9. \\
\hline thermodynamic quality of solvent & termodinamička kvaliteta otapala & & 3.2.5. \\
\hline thermodynamically equivalent sphere & termodinamički ekvivalentna sfera & & 3.2.10. \\
\hline theta state & theta-stanje & & 3.2.6. \\
\hline theta temperature & theta-temperatura & $\theta$ & 3.2.7. \\
\hline translational diffusion & translacijska difuzija & & 3.4.1. \\
\hline translational diffusion coefficient & translacijski difuzijski koeficijent & $D$ & 3.4.3. \\
\hline translational frictional coefficient & translacijski koeficijent trenja & $f$ & 3.4.2. \\
\hline tube model & cijevni model & & 3.4.44. \\
\hline tube renewal & obnavljanje cijevi & & 3.4.45. \\
\hline Tung distribution & Tungova raspodjela & & 2.24 \\
\hline turbidimetric titration & turbidimetrijska titracija & & 3.5.19. \\
\hline turbidity & zamućenost $^{p}$, turbidnost ${ }^{d}$ & $\tau$ & 3.5.18. \\
\hline uniform & jednolik* $^{*}$ & & 2.3. \\
\hline uniform dispersion & jednolika disperzijap $^{p}$, uniformna disperzija ${ }^{d}$ & & 3.5.1. \\
\hline uniform polymer & jednoliki polimerp ${ }^{p}$ uniformni polimer ${ }^{d}$ & & 2.3. \\
\hline universal calibration & univerzalno umjeravanje ${ }^{p}$, univerzalna kalibracija $\mathrm{a}^{\mathrm{d}}$ & & 3.6.13. \\
\hline unperturbed conformational state & neometano konformacijsko stanje & & 1.12. \\
\hline unperturbed dimensions & neometane dimenzije & & 1.11. \\
\hline unperturbed end-to-end distance & neometana udaljenost krajeva & $r_{\mathrm{o}}$ & 1.23. \\
\hline unperturbed end-to-end distance & neometana udaljenost krajeva* & & 1.26. \\
\hline unperturbed end-to-end vector & neometani vektor krajeva & $r_{\mathrm{o}}$ & 1.21. \\
\hline unperturbed radius of gyration & neometani polumjer vrtnje & $s_{0}$ & 1.15. \\
\hline upper critical solution temperature, UCST & gornja kritična temperatura otopine, GKTO & & 3.3.11. \\
\hline virial coefficient of the chemical potential & virijalni koeficijent kemijskog potencijala & & 3.2.4. \\
\hline viscosity contraction factor & viskoznosni faktor sažimanja & & 1.49. \\
\hline viscosity function & viskoznosna funkcija & $\phi$ & 3.4.39. \\
\hline viscosity number & viskoznosni brojn & & 3.4.17. \\
\hline viscosity ratio & viskoznosni omjer ${ }^{\mathrm{n}}$ & & 3.4.15. \\
\hline viscosity-average molar-mass & viskoznosni prosjek molarne mase & $M_{\mathrm{v}}$ & 2.12 \\
\hline
\end{tabular}




\begin{tabular}{|c|c|c|c|}
\hline Engleski naziv & Hrvatski naziv (abecednim redom) & Simbol & $\begin{array}{l}\text { Broj } \\
\text { definicije }\end{array}$ \\
\hline viscosity-average molecular weight & viskoznosni prosjek molekulske težine ${ }^{n}$ & $M_{\mathrm{r}, \mathrm{v}}$ & 2.12 \\
\hline viscosity-average relative molar mass & viskoznosni prosjek relativne molarne mase & $M_{r, v}$ & 2.12. \\
\hline viscosity-average relative molecular mass & viskoznosni prosjek relativne molekulske mase & $M_{r, v}$ & 2.12. \\
\hline worm-like chain & crvoliki lanac & & 1.43. \\
\hline$z+1$-average molar-mass & $(z+1)$-prosjek molarne mase & $M_{z+1}$ & 2.11 \\
\hline z+1-average molecular weight & $(z+1)$-prosjek molekulske težine ${ }^{n}$ & $M_{r, z+1}$ & 2.11 \\
\hline$z+1$-average relative molar mass & $(z+1)$-prosjek relativne molarne mase & $M_{\mathrm{r}, \mathrm{z}+1}$ & 2.11 \\
\hline$z+1$-average relative molecular mass & $(z+1)$-prosjek relativne molekulske mase & $M_{\mathrm{r}, \mathrm{z}+1}$ & 2.11 \\
\hline z-average molar-mass & z-prosjek molarne mase & $M_{z}$ & 2.10 \\
\hline z-average molecular weight & z-prosjek molekulske težine ${ }^{n}$ & $M_{\mathrm{r}, \mathrm{z}}$ & 2.10 \\
\hline z-average relative molar mass & z-prosjek relativne molarne mase & $M_{r, z}$ & 2.10 \\
\hline z-average relative molecular mass & z-prosjek relativne molekulske mase & $M_{r, z}$ & 2.10 \\
\hline Zimm plot & Zimmov dijagram & & 3.5 .23 \\
\hline$\theta$ state & $\theta$-stanje & & 3.2.6. \\
\hline$\theta$ temperature & $\theta$-temperatura & & 3.2.7. \\
\hline$\chi$ interaction parameter & $\chi$-parametar međudjelovanja & & 3.1 .13 \\
\hline$\chi$ parameter & $\chi$-parametar & & 3.1 .13 \\
\hline
\end{tabular}

\section{Literatura}

\section{References}

1. R. G. Jones, J. Kahovec, R. Stepto, E. S. Wilks, M. Hess, T. Kitayama, W. V. Metanomski (ur.), Compendium of Polymer Terminology and Nomenclature, IUPAC recommendations 2008 (the "Purple Book"), RSC Publishing, Cambridge, 2009.

2. P. Kratochvíl, U. W. Suter, Definitions of Terms Relating to Individual Macromolecules, Their Assemblies, and Dilute Polymer Solutions (IUPAC Recommendations 1988), Pure Appl. Chem. 61 (1989) 211-241, doi: https://doi.org/10.1351/ pac198961020211, poglavlje 3 u lit. 1. Hrvatski prijevod: N. Šegudović: Definicije pojmova za pojedinačne makromolekule, njihove skupine i razrijeđene otopine polimera (preporuke IUPAC 1988., preporuke HDKI i HKD 1992.), Kem. Ind. 42(2) (1993) B1-B12.

3. IUPAC, Compendium of Chemical Terminology, 2. izd. (the "Gold Book"), sastavili A. D. McNaught, A. Wilkinson, Blackwell Scientific Publications, Oxford, UK (1997); vidi također: M. Nic, J. Jirat, B. Kosata, XML on-line ispravljena verzija: http://goldbook.iupac.org (2006.-), sadržaj objedinio A. D. Jenkins.

4. A. D. Jenkins, P. Kratochvíl, R. F. T. Stepto, U. W. Suter, Glossary of basic terms in polymer science (IUPAC Recommendations 1996), Pure Appl. Chem. 68 (1996) 2287-2311, doi: https://doi.org/10.1351/pac199668122287, poglavlje 1 u lit. 1. Hrvatski prijevod: V. Jarm, Glosar osnovnih pojmova u znanosti o polimerima (preporuke IUPAC 1996., preporuke HDKI i HKD 1998.), Kem. Ind. 47(12) (1998) B5-B19.

5. P. J. Flory, Statistical Mechanics of Chain Molecules, Interscience Publishers, London, 1969.

6. A. D. Jenkins, Stereochemical definitions and notations relating to polymers (IUPAC Recommendations 1980), Pure Appl. Chem. 53 (1981) 733-752, poglavlje 2 u lit. 1. Hrvatski prijevod: V. Jarm, Z. Smolčić Žerdik, Stereokemijske definicije i oznake koje se odnose na polimere (preporuke IUPAC 1980., preporuke HDKI i HKD 1988.), Kem. Ind. 37(10) (1988) B38-B50.

7. M. G. Kendall, Advanced Theory of Statistics, volumen 1, Charles Griffin, London, 1948.

8. R. F. T. Stepto, Dispersity in polymer science (IUPAC Recommendations 2009), Pure Appl. Chem. 81 (2009) 351-353, doi: https://doi.org/10.1351/PAC-REC-08-05-02; Erratum ibid. 81 (2009) 781, doi: https://doi.org/10.1351/PACREC-08-05-02 erratum. Hrvatski prijevod: M. Rogošić, Disperznost u polimernoj znanosti (preporuke IUPAC 2009., preporuke HDKI i HKD 2012.), Kem. Ind. 61 (5-6) (2012) 305-309.

9. W. J. Work, K. Horie, M. Hess, R. F. T. Stepto, Definitions of terms related to polymer blends, composites, and multiphase polymeric materials (IUPAC Recommendations 2004), Pure Appl. Chem. 76 (2004) 1985-2007, doi: https:// doi.org/10.1351/pac200476111985, poglavlje 9 u lit. 1. Hrvatski prijevod: G. Bogdanić, A. Erceg Kuzmić, R. Vuković, Definicije osnovnih pojmova koji se odnose na polimerne mješavine, kompozite i višefazne polimerne materijale (preporuke IUPAC 2004., preporuke HDKI i HKD 2009.), Kem. Ind. 58(9) (2009) 387-403.

10. A. E. Alexander, P. Johnson, Colloid Science, poglavlje XIV, Oxford University Press, Oxford, 1950.

11. C. Tanford, Physical Chemistry of Macromolecules, poglavlje 6, John Wiley, New York, 1961.

12. B. J. Berne, R. Pecora, Dynamic Light Scattering with Applications to Chemistry, Biology and Physics, John Wiley, New York, 1976.

13. Popis uključuje i nazive obrađene u Kem. Ind. 66 (3-4) (2017) 145-156. (I. dio, brojevi definicija 1.1 do 2.28) i Kem. Ind. 66 (5-6) (2017) 267-278) (II. dio, brojevi definicija 3.1 do 3.4.46)

14. Napomena prevoditelja: *Nazivi koji su spomenuti u definicijama, ali nisu zasebno obrađeni. Oznake normativnog statusa naziva su preporučeni nazivp ${ }^{p}$ dopušteni naziv ${ }^{d}$ i nepreporučeni naziv" .

Ponovno objavljivanje ili reprodukcija ovog izvješća ili njegova pohrana i/ili širenje elektroničkim putem dopuštena je bez formalne IUPAC-ove dozvole uz uvjet jasno vidljivog isticanja izvora, s punom referencijom, oznakom za copyright (C), imenom IUPAC i godinom objavljivanja. Objavljivanje prijevoda na drugi jezik podložno je dodatnom uvjetu prethodnoga odobravanja od nadležne nacionalne organizacije pri IUPAC-u. 


\section{SUMMARY}

\section{Definitions of Terms Relating to Individual Macromolecules, Macromolecular Assemblies, Polymer Solutions, and Amorphous Bulk Polymers (Part III) \\ (IUPAC Recommendations 2014] \\ Translated by Marko Rogošić}

This document defines terms relating to the properties of individual macromolecules, macromolecular assemblies, polymer solutions, and amorphous bulk polymers. In the section on polymer solutions and amorphous bulk polymers, general and thermodynamic terms, dilute solutions, phase behaviour, transport properties, scattering methods, and separation methods are considered. The recommendations are a revision and expansion of the IUPAC terminology published in 1989 dealing with individual macromolecules, macromolecular assemblies, and dilute polymer solutions. New terms covering the principal theoretical and experimental developments that have occurred over the intervening years have been introduced. Polyelectrolytes are not included.

\section{Keywords}

Amorphous polymers, bulk polymers, IUPAC Polymer Division, macromolecular assemblies, macromolecules, polymer phase behaviour, polymer solutions, polymer thermodynamics, scattering properties, separation methods, transport properties

University of Zagreb

Faculty of Chemical Engineering and Technology

Marulićev trg 19

10000 Zagreb, Croatia
Nomenclature note Received November 30, 2015 Accepted May 18, 2016 